\title{
Hierarchically Porous Carbon Materials and LiMn2O 4 Electrodes for Electrochemical Supercapacitors
}

Shimeng Hao

Follow this and additional works at: https://researchrepository.wvu.edu/etd

\section{Recommended Citation}

Hao, Shimeng, "Hierarchically Porous Carbon Materials and LiMn2O 4 Electrodes for Electrochemical Supercapacitors" (2015). Graduate Theses, Dissertations, and Problem Reports. 5760.

https://researchrepository.wvu.edu/etd/5760

This Thesis is protected by copyright and/or related rights. It has been brought to you by the The Research Repository @ WVU with permission from the rights-holder(s). You are free to use this Thesis in any way that is permitted by the copyright and related rights legislation that applies to your use. For other uses you must obtain permission from the rights-holder(s) directly, unless additional rights are indicated by a Creative Commons license in the record and/ or on the work itself. This Thesis has been accepted for inclusion in WVU Graduate Theses, Dissertations, and Problem Reports collection by an authorized administrator of The Research Repository @ WVU. For more information, please contact researchrepository@mail.wvu.edu. 


\title{
Hierarchically Porous Carbon Materials and $\mathrm{LiMn}_{2} \mathrm{O}_{4}$ Electrodes for Electrochemical Supercapacitors
}

\author{
Shimeng Hao \\ Thesis submitted to the \\ Benjamin M. Statler College of Engineering and Mineral Resources \\ at West Virginia University
}

in partial fulfillment of the requirements for the degree of

Master of Science

In

Mechanical Engineering

Nianqiang Wu, Ph.D., Chair

Terence Musho, Ph.D.

Feng Yang, Ph.D.

Ayyakkannu Manivannan, Ph.D.

Department of Mechanical and Aerospace Engineering

Morgantown, West Virginia

2015

Keywords: Supercapacitor, energy, porous carbon, $\mathrm{LiMn}_{2} \mathrm{O}_{4}$, hierarchically porous structure, lignin Copyright 2015 [Shimeng Hao] 


\begin{abstract}
Hierarchically Porous Carbon Materials and $\mathrm{LiMn}_{2} \mathrm{O}_{4}$ Electrodes for

Electrochemical Supercapacitors
\end{abstract}

\title{
Shimeng Hao
}

Increasing energy density of electrochemical capacitors (ECs) is crucial for their applications in energy storage devices requiring short peak power pulses as well as longterm operation. ECs are operated via two primary charge mechanisms, that is, the electrochemical double-layer capacitance and the pseudocapacitance. In the thesis, the carbon materials and $\mathrm{LiMn}_{2} \mathrm{O}_{4}$, which generate double-layer capacitance and pseudocapacitance, respectively, have been investigated. The effects of specific surface area, pore structure and surface functionality on the energy storage performance of ECS have been studied.

Micro-porous $(<2 \mathrm{~nm})$ carbon with pores inaccessible to the solvated ions may limit the ion diffusion, resulting in a low rate capability. Hence this work attempts to generate hierarchical macropores/mesopores/micropores in the electrode material. Flexible, self-sustained and hierarchical porous carbon nanofibers (CNFs) are fabricated using terephthalic acid as the sacrificial agent. After sublimation and carbonization, the electrospun mat is converted to a hierarchical porous carbon framework. The high specific capacitance and good rate capability are associated with the unique hierarchical porous structure of the as-prepared CNFs. Both the outer fiber surface and inner porous structure can be accessible for charge accumulation through pores on the surface. Hierarchical macropores/mesopores in the fiber also help accelerate the ion-diffusion into inner micropores.

Besides fossil resources, renewable biomass has also been explored as the source material for supercapacitors in the present work. Lignin, the major aromatic constituent of plant and woods, is utilized as the carbon precursor to prepare the mesoporous ligninchar. The lignin-derived carbon is prepared by taking an advantage of the organic-organic self-assembly method, which allows the direct formation of mesoporous polymer composite from carbon precursor and block copolymer, and conversion to porous carbon by carbonization. Hierarchically porous carbon (HPC) with pores at different scales has been obtained after alkali activation. The experimental results show that the appropriate pore size distribution can ensure high power density and high energy density due to the short diffusion distance and the minimized electric resistance. Utilization of biomass as the source materials for supercapacitors will reduce the costs for fabrication of energy storage devices. 
Developing asymmetric supercapacitors is an alternative effective way to obtain high energy density for an enlarged potential window and additional pseudocapacitance. $\mathrm{LiMn}_{2} \mathrm{O}_{4}$ nanoparticles have been fabricated with a facile and cost-effective method using carbon black as the template. The spinel structured $\mathrm{LiMn}_{2} \mathrm{O}_{4}$ exhibits a high specific capacitance in a three-electrode system. An asymmetric supercapacitor has been made with the as-prepared $\mathrm{LiMn}_{2} \mathrm{O}_{4}$ nanoparticle as the cathode and the commercial activated carbon as the anode in a $\mathrm{Li}_{2} \mathrm{SO}_{4}$ aqueous solution. The asymmetric supercapacitor shows a good energy capacity and excellent cycling stability. 


\section{Acknowledgements}

I would like to thank my supervisor Professor Nianqiang (Nick) Wu for his

intellectual guidance and invaluable instructions in my 3-year studies for Master of Science degree in West Virginia University.

I would also like to thank my committee members Dr. Terence Musho, Dr. Feng Yang and Dr. Ayyakkannu Manivannan for their advice and help on my thesis.

In addition, I would like to express my thanks to Dr. Weiqiang Ding, Dr. James Poston for their support of materials characterization with XPS and XRD.

Special thanks to Dr. Jiangtian Li for his valuable advice and help on my research. I am also grateful to Peng Zheng, Joeseph Bright, Sujan Phani Kumar Kasani, Dr. Scott Cushing, Savan Suri, Dr. Jianliang Cao, Dr. Yan Wang, Dr. Hualei Zhou, Dr. Xuefei Gao,.Yang He for their help in academic field and everyday life.

Finally, I wish to express my sincere appreciation to my friends and family for their encouragement and support throughout all the time. 


\section{Table of Contents}

Chapter 1 Introduction......................................................................................................... 1

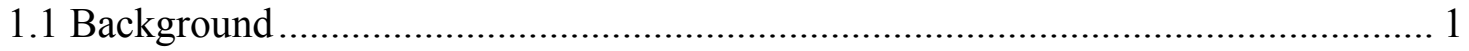

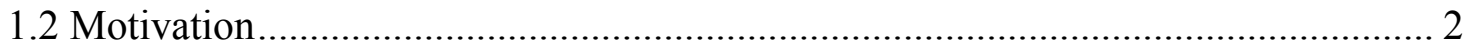

1.3 Significance

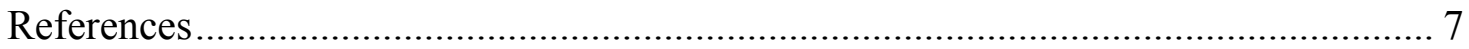

Chapter 2 Literature Review ............................................................................................... 9

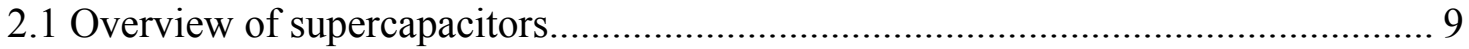

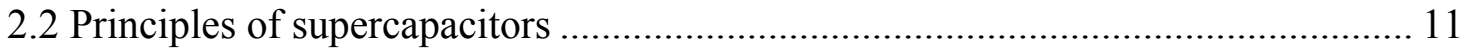

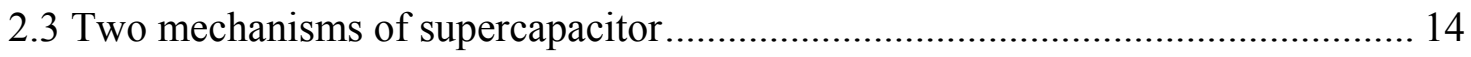

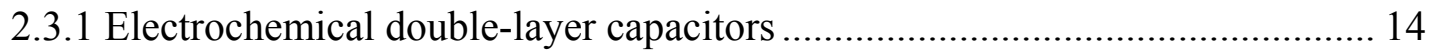

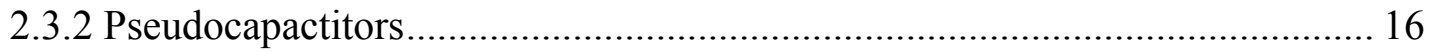

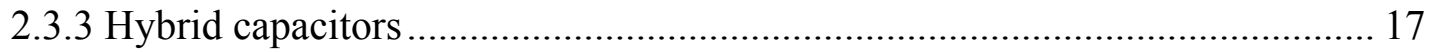

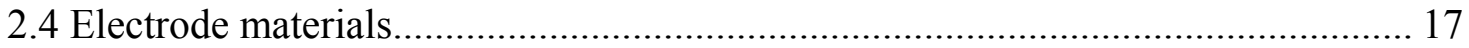

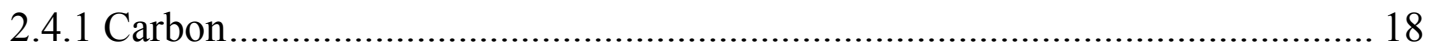

2.4.2 Pseudocapacitive materials ...................................................................... 20

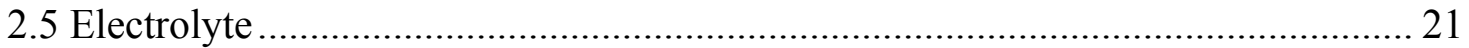

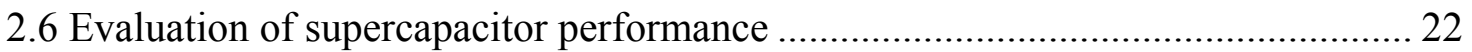

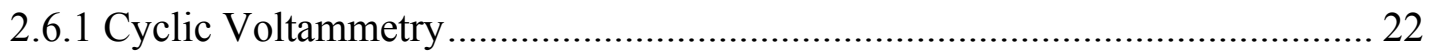

2.6.2 Constant Current Charge-Discharge Test ..................................................... 22

2.6.3 Electrochemical Impedance Spectroscopy .................................................... 23

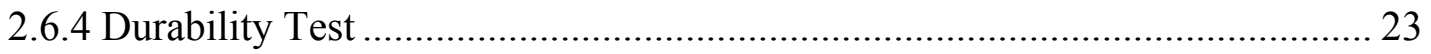

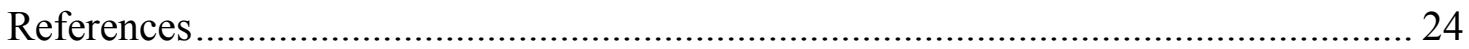

Chapter 3 Hierarchically Porous Carbon Nanofiber as Flexible Electrode for Symmetric Supercapacitor................................................................................................ 29

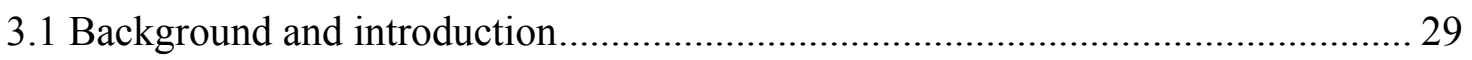

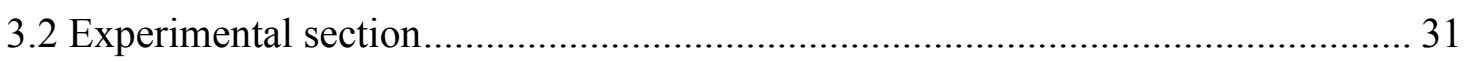

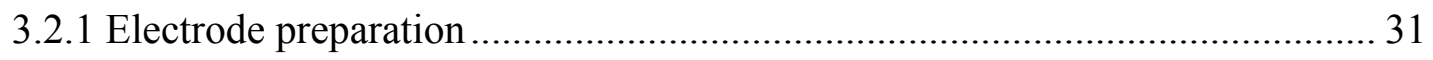

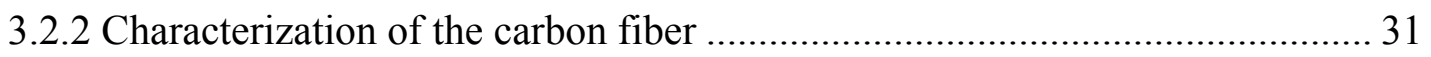

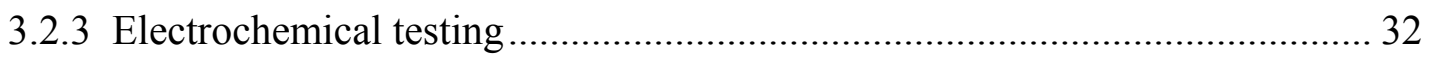

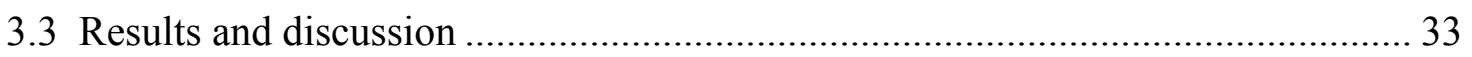

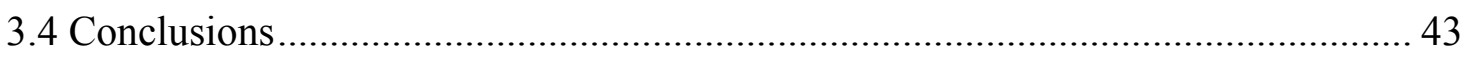

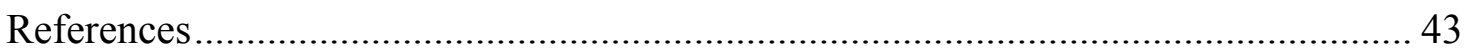


Chapter 4 Asymmetric Supercapacitors from Nano-architectured $\mathrm{LiMn}_{2} \mathrm{O}_{4} / /$ Activated Carbon Electrodes ............................................................................................... 47

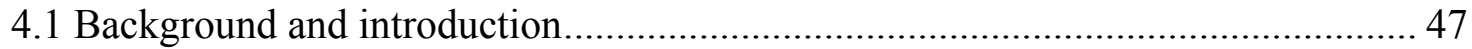

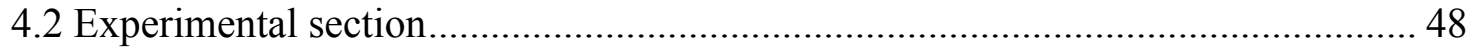

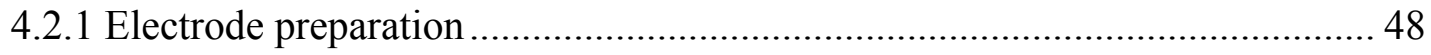

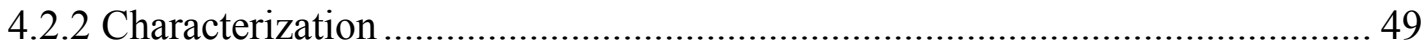

4.2.3 Electrochemical characterization ................................................................... 49

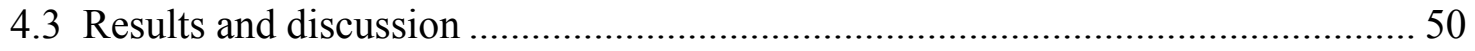

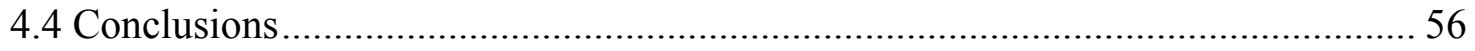

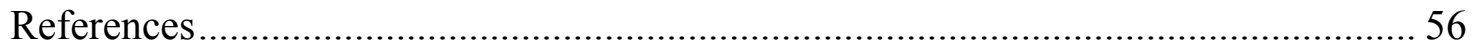

Chapter 5 Lignin-derived Hierarchically Porous Carbon Prepared by a Selfassembly Method for Electrochemical Supercapacitor......................................................60 60

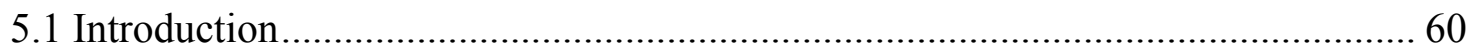

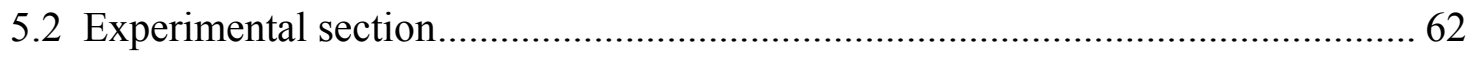

5.2.1 Synthesis of lignin-derived hierarchically porous carbon ……………............ 62

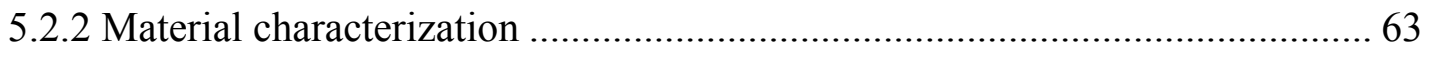

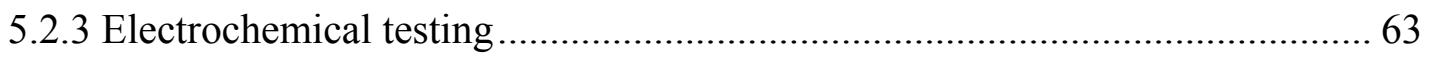

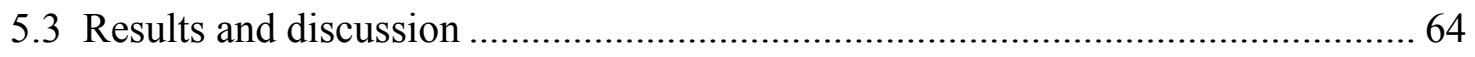

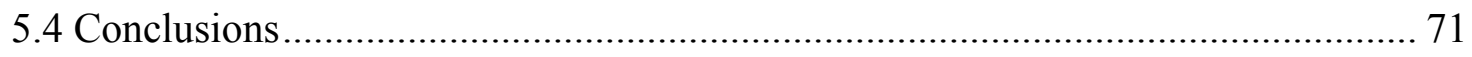

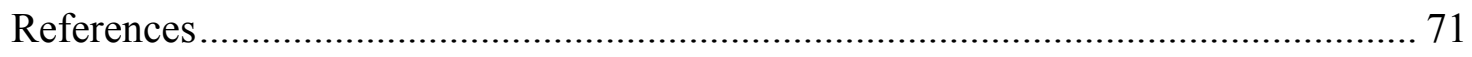

Chapter 6 Conclusions........................................................................................................ 73 


\section{Chapter 1 Introduction}

\subsection{Background}

Energy storage is to balance the supply and demand of energy and is becoming a key factor in economic growth with the widespread application of electricity. Renewable energy (most notably solar and wind) contributed 19\% to the energy consumption and $22 \%$ to the electricity generation in 2012 and 2013 based on REN21's 2014 report [1]. However, the intermittent renewable energy sources limit continuous electricity power supply and effective electric energy storage systems are in great demand to capture excess energy during periods of low demand.

Principles of electrical energy storage are divided into two types: chemical energy storage and capacitive energy storage. Batteries store energy in the form of chemical reactants whereas electrochemical capacitors (ECs) store energy as charge. Although batteries are ubiquitous in today's potable electronic devices because of recent improvements in engineering and chemistry, to meet the requirements of high power recovery-supply or high charge-discharge cyclability in some application devices remains a challenge. For example, only energy storage devices with fast charging rate can capture energy which is currently wasted in many repetitive processes such as braking in automobiles and descending elevators. Rather than the phase and crystalline structure changes caused by the faradaic charging-discharging in batteries, no major changes take place when ECs store electrical charge. Therefore, the ECs systems can undergo a large number of charging-discharging cycles (up to millions) with high stability and reliability. 
Furthermore, this storage mechanism is particularly adapted for applications which require fast charging-discharging rate (within seconds).

The world market of batteries is estimated to be $\$ 95$ billion while that of supercapacitors is only $\$ 400$ million in 2013 [2]. To fully harness ECs' potential as energy storage systems, it is essential to develop ECs with higher energy density and lower costs. [3].

\subsection{Motivation}

To satisfy the industrial demands and realize the full potential of ECs as electrical energy storage devices, new electrode materials/design should be proposed and fundamental understanding of the physical and chemical processes at the interface is required. The field of ECs has been strongly influenced by battery technology which is evident by the construction of similar electrode materials. Two active layers, one separator with electrolytes are the basic component elements of both the two kinds of energy storage systems. Carbon can be used as anodes, transition-metal oxides as cathodes, and sulfuric acid or acetonitrile can serve as electrolytes [4], which are much like the construction of batteries. However, electrode/electrolyte materials should be designed specific to ECs due to the different mechanisms between the two storage systems [5].

High costs and low-energy storage have been considered as the major obstacles for ECs to meet demands of energy storage device requiring short peak power pulses as well as long-term operation [6]. Natural precursors or biomass materials have been widely investigated in recent years as nanostructured activated carbon electrodes for 
electrical double layer capacitors (EDLCs), motivated in large part by their low-cost, high specific surface area, high electrical conductivity, high stability, environmental friendly character and ease of synthesis and processing [7-10]. The total carbon mass of biomass production is estimated to be 104.9 petagram $\left(104.9 \times 10^{15} \mathrm{~g}\right)$ per year [11]. The great abundance of carbon sources makes biomass-derived carbon promising candidates for low cost and mass-production of carbon-based EDLCs. Different physical and chemical activation methods can lead to extensively developed porosity and high value of specific surface area $\left(\sim 2400 \mathrm{~m}^{2} \mathrm{~g}^{-1}\right)$ [12]. However, highly micro-porous $(<2 \mathrm{~nm})$ carbons limits the ion diffusion in case of smaller pores compared to the solvated ions, resulting in lower capacitance at high-rate charge/discharge rate. A 3D hierarchical porous carbon design is proposed and macro-pores $(>50 \mathrm{~nm})$, meso-pores $(2 \sim 50 \mathrm{~nm})$ and micro-pores $(<2 \mathrm{~nm})$ are combined to achieve improved power density and energy density at high rate [13], because the macro-pores can minimize the diffusion distances, the meso-pores offer low-resistant ion transport pathways for the electrolyte ions whereas the micro-pores contribute to the capacitance values $[14,15]$. Besides the consideration of pore-size distribution, other factors such as surface functionality, hydrophilicity, electrical conductivity also play an important role in energy storage performance of carbon electrode [16]. Therefore, even if good performance is achieved with well-developed porosity, the other parameters are important considerations and worth further investigation to make this system applicable in energy storage.

Electrospinning- drawing submicrometer fibers from a liquid by an electrical charge-is a powerful technique for the fabrication of one-dimensional (1D) nanostructured fibers. Polyacrylonitrile is a widely-used polymer precursor for 
electrospinning process due to its good electrospinnabilty. Upon the following carbonization treatment, continuous carbon nanofibers (CNFs) are easily produced with nano-scale diameter, large surface-to-volume ratio, large surface area and high conductivity. To further enhance the application of electrospun carbon fiber, optimizing composite precursor has been utilized to increase the surface area and porosity of carbon fibers by selective removal of one component in the composite [17], which provides a cost-effective synthetic route to control internal fiber structure (e.g. pore size distribution) in the porous carbon fiber. Different kinds of pores (micro-, meso-, macro-) can be generated with variations of precursor options. In addition, the electrospinning parameters and the carbonization temperature are responsible for the final carbon fiber diameter, surface morphology, the degree of graphitization and electrical conductivity, which affect the capacitance and rate capability of CNFs-based electrochemical capacitors. Another practical issue is that the CNFs fabricated after carbonization is usually brittle, and flexible CNFs which can be integrated into the wearable electrical devices are in great demand in industry. All the above challenges should be overcome before the industrial application of CNFs as supercapacitors.

Pseudocapacitor, besides EDLCs, is the other type of electrochemical capacitors. Its operation is based on electrosorption, reduction-oxidation reactions, and intercalation processes instead of a Faradaic process. Therefore, it possesses intrinsically higher capacitance and energy density than EDLCs. However, the high cost (e.g. $\left.\mathrm{RuO}_{2}\right)$ and low conductivity (e.g. $\mathrm{MnO}_{2}$ ) have limited its potential application $[18,19]$. Asymmetric hybrid capacitor, which combines Faradaic and non-Faradaic processes, is a promising system to exploit both the charge/discharge of capacitive double-layer and that of 
pseudocapacitive materials. EDLCs-type electrode may provide high power density while pseudocapacitve materials provide high energy density. Investigation into the novel and rational electrodes design may lead to electrochemical supercapacitors that store more energy at higher charge/discharge rate.

In this thesis, experiments are designed and conducted based on two different types of energy storage mechanisms in electrochemical capacitors: double layer charge capacitance and pseudocapacitance. Tailored nanostructured materials are developed to enable fast ion transport, high conductivity and high surface area. Apart from the scientific quest for active materials with high energy density and power density, flexible EDLCs are also fabricated to realize its incorporation into wearable energy storage devices.

The thesis presents a brief introduction of the work involving the background and motivation. In chapter 2, a literature review is provided based on the progress of electrochemical supercapacitor in recent years. Following the introduction and review section, in chapter 3 , we provide a facile route to fabrication of flexible carbon nanofibers with hierarchically porous structure via electrospinning. In chapter $4, \mathrm{LiMn}_{2} \mathrm{O}_{4}$ nanoparticles were fabricated with a facile and cost-effective method by using carbon black as template. An asymmetric supercapacitor was made with the as-prepared $\mathrm{LiMn}_{2} \mathrm{O}_{4}$ nanoparticle as the cathode and the commercial activated carbon as the anode working in $\mathrm{Li}_{2} \mathrm{SO}_{4}$ aqueous solution. In chapter 5, we utilized lignin as carbon precursor to prepare mesoporous lignin-char. Hierarchically porous carbon with pores at different scales were obtained after alkali activation. The effects of specific surface area and hierarchical porous nano-structure on the energy capacity are discussed. 


\subsection{Significance}

In the thesis, we present the fabrication processes of three types of active materials for electrochemical capacitors. The unique hierarchical pore structure and nanostructure exhibit high performance in energy storage. The results will not only be helpful to the future design of advanced electrode materials and configurations, but also be beneficial to better understand the physical and chemical processes at the electrode/electrolyte interface. Ions in the electrolyte cross the pore space onto the surface of carbon via diffusion, but too small or tortuous micropores may hinder the ion transport. For the as-prepared carbon nanofibers, both the outer fiber surface and inner pores can be accessible for charge accumulation through pores on the surface. Hierarchical macropores/mesopores in the fiber are also beneficial to accelerate the iondiffusion into inner micropores. In the hierarchically porous carbon design, macro-pores, meso-pores and micro-pores are combined to achieve improved power density and energy density at the same time: the macro-pores can minimize the diffusion distance, the meso-pores accelerates ion-transport whereas the micro-pores contributes to the capacitance values. Cost is another consideration for electrochemical capacitors to meet demands of energy storage. The utilization of lignin, the major aromatic constituent of plant and woods, enables potential applications in low-cost energy storage devices. These electrodes materials are promising candidates for high-performance electrochemical capacitors. 


\section{References}

[1] REN21. Renewables 2014: Global Status Report. (2014).

[2] Dennis Zogbi, Paumanok Group. Supercapacitors the Myth, the Potential and the Reality. (2013)

[3] Kötz, R., and M. Carlen. "Principles and applications of electrochemical capacitors." Electrochimica Acta 45 (2000): 2483-2498.

[4] Pandolfo, A. G., and A. F. Hollenkamp. "Carbon properties and their role in supercapacitors." Journal of power sources 157 (2006): 11-27.

[5] Goodenough, J. B., H. D. Abruña, and M. V. Buchanan. "Basic Research Needs for Electrical Energy Storage: Report of the Basic Energy Sciences Workshop on Electrical Energy Storage, 2007 Apr 04. US Department of Energy."

[6] Zhang, Jiujun, et al., eds. Electrochemical technologies for energy storage and conversion. John Wiley \& Sons, 2012.

[7] Kötz, R., and M. Carlen. "Principles and applications of electrochemical capacitors." Electrochimica Acta 45 (2000): 2483-2498.

[8] Frackowiak, Elzbieta, and Francois Beguin. "Carbon materials for the electrochemical storage of energy in capacitors." Carbon 39 (2001): 937-950.

[9] Pandolfo, A. G., and A. F. Hollenkamp. "Carbon properties and their role in supercapacitors." Journal of power sources 157 (2006): 11-27.

[10] Wei, Lu, and Gleb Yushin. "Nanostructured activated carbons from natural precursors for electrical double layer capacitors." Nano Energy 1 (2012): 552-565. [11] Field, Christopher B., et al. "Primary production of the biosphere: integrating terrestrial and oceanic components." Science 281 (1998): 237-240. 
[12] Zhu, Yanwu, et al. "Carbon-based supercapacitors produced by activation of graphene." Science 332 (2011): 1537-1541.

[13] Wang, Da - Wei, et al. "3D aperiodic hierarchical porous graphitic carbon material for high - rate electrochemical capacitive energy storage." Angewandte Chemie 120 (2008): 379-382.

[14] Xing, W., et al. "Superior electric double layer capacitors using ordered mesoporous carbons." Carbon 44 (2006): 216-224.

[15] Chmiola, John, et al. "Anomalous increase in carbon capacitance at pore sizes less than 1 nanometer." Science 313 (2006): 1760-1763.

[16] Gogotsi, Yury, ed. Nanomaterials handbook. CRC press, 2006.

[17] Huang, Zheng-Ming, et al. "A review on polymer nanofibers by electrospinning and their applications in nanocomposites." Composites science and technology 63 (2003): 2223-2253.

[18] Abruña, Héctor D., Yasuyuki Kiya, and Jay C. Henderson. "Batteries and electrochemical capacitors." Phys. Today 61 (2008): 43-47.

[19] Bélanger, Daniel, L. Brousse, and Jeffrey W. Long. "Manganese oxides: battery materials make the leap to electrochemical capacitors." The Electrochemical Society Interface 17.1 (2008): 49. 


\section{Chapter 2 Literature Review}

\subsection{Overview of supercapacitors}

In 1853, Helmholtz showed that electrical double-layer (DL) could be used to store charge based on the fact that charged electrodes immersed into electrolyte repel the co-ions and attract counterions in the interface [1]. The first patent on porous carbon electrodes in sulfuric acid electrolyte to store electrical energy was described in 1957 by Becker for General Electric [2]. It was believed that high specific capacitances (around 5$50 \mu \mathrm{F} \mathrm{cm} \mathrm{cm}^{-2}$ ) could be obtained for carbons with high surface area in molten salts or aqueous electrolytes [3]. NEC developed aqueous electrolyte/activated carbon capacitors as "supercapacitors" in 1971 by licensing the technology of SOHIO [4]. In the following two decades, Panasonic and ELNA marketed the first generation of EDLCs which were mainly used for low current applications such as memory backup devices due to relatively high internal resistance [4,5]. Supercapacitors with low internal resistance were developed, which were used for the U.S. military applications with the Pinnacle Research Institute (PRI) in 1982 [6].

Inspired by the work on conventional electrochemical battery, researchers studied another kind of supercapacitors (pseudopcapcitors) working in a different mechanism. Pseudocapacitors store energy through electrosorption, redox reactions, and intercalation processes rather than an electrostatical double-layer charging process in the EDLCs [7-9]. By deposition onto conductive metallic substrates, conducting polymers and transitionalmetal oxides (ruthenium oxide, nickel oxide, iridium dioxide) exhibited a higher energy density than EDLCs. 
In 2007, Department of Energy assessed the technologies on electrical storage and specifically showed the increasing potential of electrochemical capacitors in hybrid electric vehicle (HEV), portable devices and residential application [10]. Worldwide sales of supercapacitor reached $\$ 400$ million in 2010 and it is estimated to be $\$ 3.0$ billion by 2016 according to Nanomarkets [11]. A number of companies including Ness, Panosonic, Maxwell, EPCOS and ESMA have successfully marketed commercial ECs. Although being able to deliver higher power per unit mass (Ragone plot, Figure 2-1), ECs store lower energy than batteries which are widely used in a large range of electrical applications. So far, the low energy density of ECs has been considered the main challenge and a variety of electrodes have been developed to improve the energy storage. Among them, activated carbons [12], carbon aerogels [13], carbon nanotubes [14], graphenes [15] and carbon nanofibers [16] were investigated as ECs electrodes due to their high electrical conductivity, stable physiochemical properties and versatility of nano-structures. Recently, different kinds of porous structures (micro-, meso-, macro-) have exhibited potential in improving the capacitance by either raising specific surface area or minimizing ion transport resistance $[17,18]$. The accessible submicrometer pores in the hierarchical porous structures may place an important role in enhancing the energy density of porous carbons, especially those templated carbon materials. 


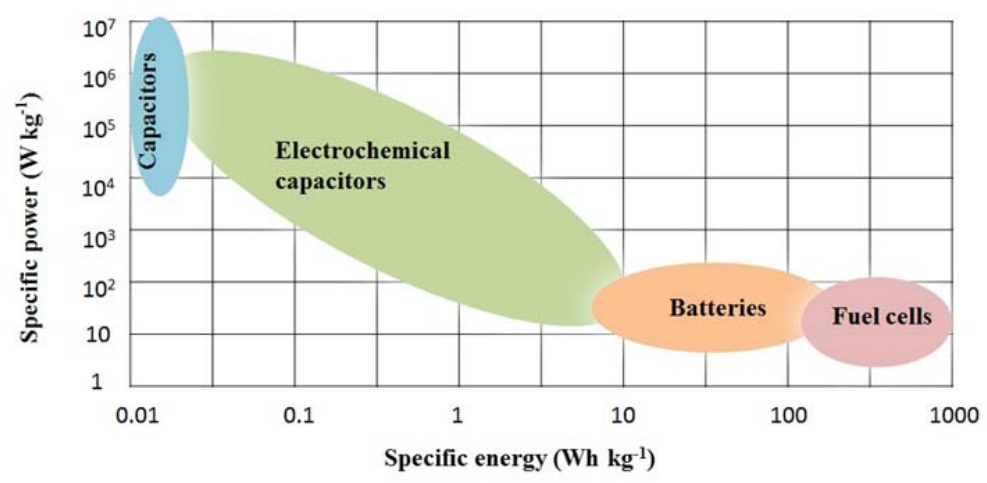

Figure 2-1 Ragone plot of energy storage and conversion devices

Many researches focus on the design of composite electrodes or asymmetric hybrid capacitors, which can mitigate the disadvantages of EDLCs and pseducapacitors to reach higher energy density. Companies such as Fuji Heavy Industry, ESMA and CSIRO are also developing asymmetric hybrid capacitors for commercial devices [19-21].

Fundamental understanding and rational design of ECs will lead to a significant increase of energy density while maintaining the feature of high power density. The study upon tailored porous structure, surface functionality, electrodes design is desirable to convert the potential of ECs into applications in energy storage field.

\subsection{Principles of supercapacitors}

Conventional capacitors consist of two electrodes separated by one insulating dielectric. When a voltage is applied to the system, charges of opposite polarity accumulate on the surfaces. Thus energy is stored in the form of electric field. The schematic of capacitors is illustrated in Figure 2-2. 


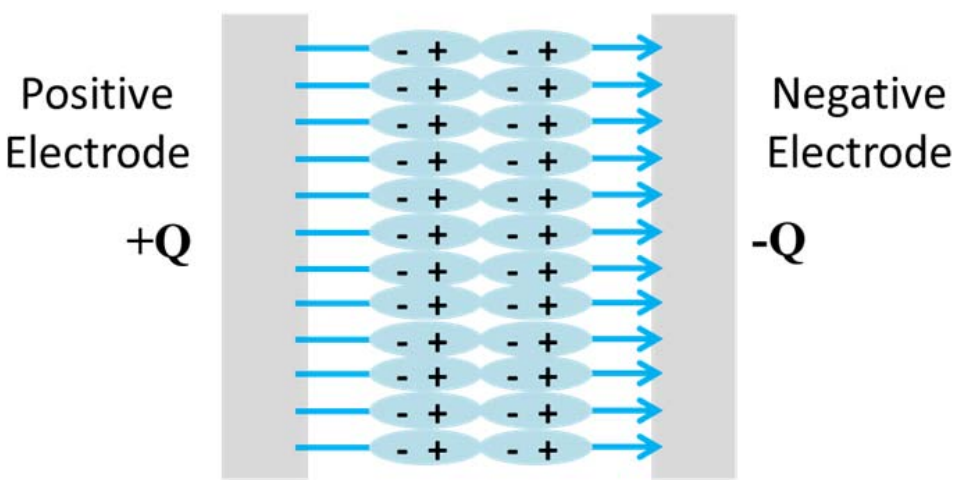

dielectric

Figure 2-2 Schematic of a conventional capacitor

The capacitance of an ideal capacitor is a constant and it is defined as the ratio of accumulated charge $Q$ to the applied voltage $V$.

$$
C=\frac{Q}{V}
$$

In the parallel-plate model, the capacitance $C$ of two parallel plates separated (separation $D$ ) by a dielectric (permittivity $\varepsilon$ ) over an area $A$ is

$$
C=\varepsilon \frac{A}{D}
$$

The maximum energy stored in a capacitor with a voltage $U$ loaded between the two plates is given by [22]:

$$
E=\frac{1}{2} C U^{2}
$$

The power $\left(P_{\max }\right)$ is calculated by equation [3]:

$$
P_{\text {max }}=\frac{U^{2}}{4 R}
$$

Where $R$ is the equivalent series resistance (ESR). Electrodes, dielectric materials and current collectors all contribute to the ultimate resistance. 


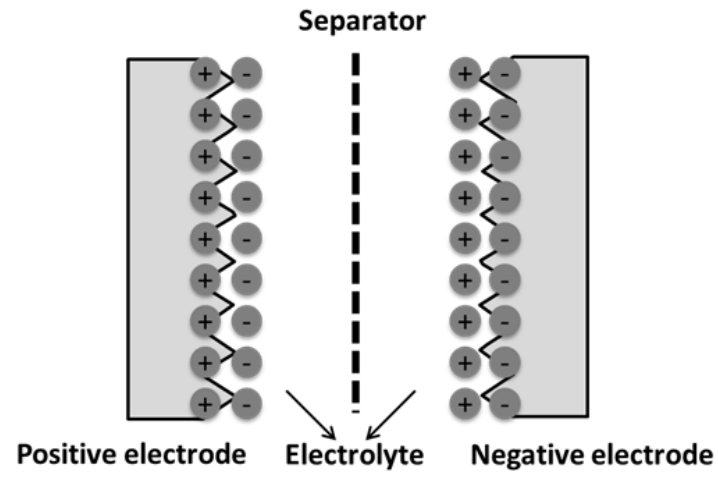

Figure 2-3 Schematic of an electrochemical double-layer capacitor

In the same way as conventional capacitors store electrical charges between two electrodes, supercapacitors accept and deliver charges by a potential applied during charging/discharging process. Actually, there's a much thinner "dielectric" and much higher surface area in supercapacitor which distinguishes them from conventional capacitors. According to equation 2-2, capacitance is much greater for capacitors with a high permittivity $\varepsilon$, a higher surface area $A$ and a shorter distance $d$. Typically, activated carbon has an extremely high surface area up to $1000 \sim 3000 \mathrm{~m}^{2} \mathrm{~g}^{-1}$ [23]. For electrochemical double-layer capacitors, the double-layer distance is as thin as only a few angstroms $(0.3 \sim 0.8 \mathrm{~nm})[24,25]$. As a result, supercapacitors store almost 10 100 times more energy per unit mass than conventional capacitors (from equations 2-2 and 2-3). Figure 2-3 is the schematic of EDLCs which provides some physical features different from conventional capacitors in Figure 2-2.

As referred to above, Ragone plot (Figure 2-1) is a useful tool to compare energy density as well as power density together among different energy storage devices. Supercapacitors, with a higher energy density than conventional capacitors and higher 
power density than batteries bridge the gap between conventional capacitors and rechargeable batteries.

\subsection{Two mechanisms of supercapacitor}

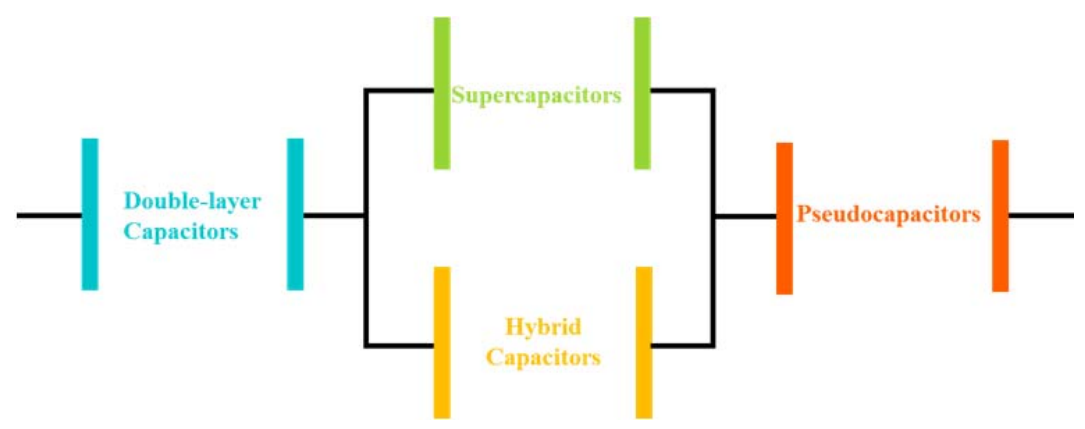

Figure 2-4 Taxonomy of supercapacitor

There are primarily two types of charge mechanisms for the operation of supercapacitor [26]. The design of the first generation of commercial ECs since its discovery is based on the principle of double-layer capacitance. Another form of ECs, pseudocapacitors store energy due to Faradaic electron charge transfer. The energy storage of hybrid capacitors is partially from non-Faradaic capacitance and partially from Faradaic capacitance. In other words, it's a combination of these two mechanisms.

\subsubsection{Electrochemical double-layer capacitors}

EDLCs store charge electrostatically without charge transfer between electrodes and electrolyte, similar to those conventional capacitors except that the double-layer thickness is only of a single molecule. As it means literally, "double-layer" is composed 
of two layers of charges: one is in the surface lattice structure of the electrode and the other one is solvated ions in the electrolyte. The two layers are charged with opposite polarity and separated by a monolayer of solvent molecules (inner Helmholtz plane). Due to the fact that the interaction between these two layers is physical electrostatic forces rather than chemical bonds the lifetime of EDLCs is unlimited in principle, which stands out compared with that of batteries (typically 400 1200 cycles for lithium-ion battery). The ions in double-layers move through diffusion in the electrolyte. As a result, the moving speed of ions in the electrolyte and the porous structure of the electrodes both contribute to the resistance of the EDLCs. In the case of EDLCs with insignificant resistance, the capacitance can be described by the equation below:

$$
F / g=\left(F / m^{2}\right) *\left(m^{2} / g\right)
$$

Where $\mathrm{F} / \mathrm{m}^{2}$ is the capacitance per unit area of active surface and $\mathrm{m}^{2} \mathrm{~g}^{-1}$ is the specific surface area. The value of capacitance per unit area is as high as $0.15 \sim 0.3 \mathrm{Fm}^{-2}$ because of the extremely thin double layer distance $(0.3 \sim 0.8 \mathrm{~nm})$ [7]. Specific capacitance can reach 150 300 $\mathrm{Fg}^{-1}$ for EDLCs with surface area at $1000 \mathrm{~m}^{2} \mathrm{~g}^{-1}$ (typical value for activated carbon). Equation (2-5) is not considered applicable for EDLCs with high surface area most contributed by small pores $(<1 \mathrm{~nm})$ which can't be accessed by ions in the electrolyte [27].

Overall, surface characteristics that can limit the performance of EDLCs are listed below:

(1) electrical conductivity;

(2) specific surface area;

(3) pore size distribution; 
(4) interconnection of porous structure;

(5) wettability.

\subsubsection{Pseudocapactitors}

Alternative to EDLCs, pseudocapacitors store charges faradaically by electron charge-transfer involving redox reactions, intercalation (doping/undoping) or electrosorption. The charge transferred in this mechanism is voltage-dependent due to thermodynamic reasons. The average capacitance can be calculated from:

$$
C=Q / U
$$

Where $\mathrm{Q}$ and $\mathrm{U}$ are the total charge accumulated and voltage range respectively for charging/discharging processes.

The charge transfer processes take place at the interface and in the bulk near the surface for pseudocapacitors and thus the specific capacitance often exhibit higher energy densities than EDLCs (10-100 times [28]). Common materials used for pseudocapacitors are metal oxide $\left(\mathrm{RuO}_{2}, \mathrm{MnO}_{2}\right.$ and so on) and conducting polymer (polyaniline PANI, polypyrrole $\mathrm{PPy}$, etc.). $\mathrm{RuO}_{2}$ has shown excellent performance, but the high cost and toxicity of $\mathrm{RuO}_{2}$ hinders its practical purposes [29]. As for other metal oxide (typically $\mathrm{MnO}_{2}$ ), the performance suffers poor electrical conductivity and dissolution effect [30]. For conducting polymers, improvement in redox stability is required by alleviating the mechanical stress occurring during swelling and shrinking cycles [31]. 


\subsubsection{Hybrid capacitors}

Classified by the electrode configuration, hybrid capacitors primarily consist of composite, asymmetric, and battery-type.

Composite-type capacitors incorporate carbon materials with metal oxide/conducting materials. The component of carbon materials is able to not only provide a conductive framework with high specific surface area but also contribute double-layer capacitance. Furthermore, conducting polymer or metal oxide can enhance the total energy density through pseudocapacitance mechanism [32].

Asymmetric capacitors combine the two energy storage mechanisms for ECs by utilizing different materials for positive and negative electrodes. Generally, carbon materials with high hydrogen evolution overpotential are used as anode and conducting polymer or metal oxide as cathode [33]. This design of electrodes can enlarge the operating window in aqueous electrolyte and eventually improve the energy density according to equation (2-3). The electrode configuration of battery-type capacitors is similar to that of asymmetric capacitors except the utilization of battery-type electrode as cathode instead of conducting polymer/metal oxide.

\subsection{Electrode materials}

Managing functionality, porous structure and electrical characteristics of ECs is key for application of supercapacitors. Electrodes with high electrical conductivity, physicochemical stability, high specific surface area, environmental friendliness and low cost are preferred to construct energy storage devices. A variety of active materials have been reported to date with their specific benefits and challenges. 


\subsubsection{Carbon}

Carbon is the most commonly used electrode component for ECs. The advantages of carbon materials are listed below:

(1) high specific surface area;

(2) high conductivity;

(3) high temperature stability;

(4) high corrosion resistance;

(5) versatility of carbon forms and nanostructures ;

(6) low cost

Activated carbon Activated carbon is the most widely used electrode material in commercial supercapacitors. Activated carbon is usually derived from biomass and charcoal and is considered as a cost-effective material in energy storage application. Upon different carbonization/activation temperatures, activated carbon consists of amorphous carbon, ordered graphite, and materials with different levels of graphitization. A broad range of pore sizes, micropores $(<2 \mathrm{~nm})$, mesopores $(2-50 \mathrm{~nm})$ and macropores $(>50 \mathrm{~nm})$ can be developed by activation of carbon materials, though the pore structure is ill-defined and unoptimized. The pores within activated carbon are highly tortuous with a random pore size distribution, which can limit ion transportation. Theoretically, the double-layer capacitance of EDLCs partially relies on the specific surface area of the activated carbons. However, empirical evidence shows that not all of the surface area contributes to the capacitance improvement, which is explained by the inaccessibility of the microporosity developed during activation [34]. Methods to develop an inter- 
connected porous framework with tailored pore sizes are needed for further utilization of activated carbon.

Templated carbons The template method allows for the preparation of carbons with well-defined and interconnected porous structure. Two types of templates, soft template and hard template are used to create pores into carbon precursor. The hard template method involves the incorporation of carbon precursor into a prepared porous template, carbonization of the composite and removal of the template. Alternatively, the soft template approach involves introduction of surfactants to carbon precursor. In both cases of the above two methods, the carbon precursor turned out to be carbon framework with well-defined pore size, which proved to be able to expedite ion diffusion and trapping of ions in micropores near larger pores [35]. As a result, a higher energy density could be achieved while maintaining a good rate capability.

Graphene Graphene possesses a unique single-layer two-dimensional structure with a high surface area, high mechanical strength and excellent electric conductivity $\left(\sim 200 \mathrm{Sm}^{-1}\right)$. Wang et al. fabricated graphene electrode as ECs of a high capacitance of $205 \mathrm{Fg}^{-1}$ [36]. In 2007, Department of Energy assessed the technologies on electrical storage and predicted that graphene, due to its metallic conductivity, low-weight and excellent corrosion resistance, may act as carbon current collector which can be assembled directly with porous materials to obtain a fundamental decrease in ESR values [10]. Furthermore, graphene also exhibit flexibility and transparency properties. Yu et al. reported on a thin-film of graphene $(25 \mathrm{~nm})$ with $70 \%$ optical transparency as ECs [37].

Carbon nanofibers Carbon nanofibers can be fabricated by a simple and costefficient approach: electrospinning. As a one-dimensional nanostructure, carbon 
nanofiber can facilitate charge transport [38] and can also serve as a substrate to integrate with pseudocapacitive materials to enhance energy density.

\subsubsection{Pseudocapacitive materials}

Transition metal oxides that can be used as ECs include ruthenium dioxide $\left(\mathrm{RuO}_{2}\right)$, manganese dioxide $\left(\mathrm{MnO}_{2}\right)$, vanadium pentoxide $\left(\mathrm{V}_{2} \mathrm{O}_{5}\right)$, iron oxides $\left(\mathrm{Fe}_{3} \mathrm{O}_{4}\right)$ and tin dioxide $\left(\mathrm{SnO}_{2}\right)$. Metal oxide exhibits a sequence of redox reactions to form an almost rectangular $\mathrm{CV}$ curve due to a number of oxidation states at different potentials. In contrast, conductive polymers exhibit current peaks at specific redox potentials.

Metal Oxides.... $\mathrm{RuO}_{2}$ is a promising electrode material due to its good electrical conductivity, reversible redox reactions, very high capacitance. It was reported as ECs of capacitance up to $750 \mathrm{Fg}^{-1}$ [39]. However, high cost of $\mathrm{RuO}_{2}$ capacitors and potential safety hazards limit its commercial uses in ECs. There has been great interest in $\mathrm{MnO}_{2}$ with lower cost and less safety hazards. The charging mechanism involves surface adsorption of cations and proton intercalation [40]:

$$
\left(\mathrm{MnO}_{2}\right)_{\text {surface }}+\mathrm{M}+e^{-} \leftrightarrow\left(\mathrm{MnO}_{2}{ }^{-} \mathrm{M}^{+}\right)_{\text {surface }}
$$

Where $\mathrm{M}+$ is $\mathrm{Na}+, \mathrm{K}+\ldots$

$$
\mathrm{MnO}_{2}+\delta \mathrm{H}^{+}+\delta \mathrm{e}^{-} \leftrightarrow \mathrm{H}_{\delta} \mathrm{MnO}_{2}(0<\delta<0.5)
$$

The capacitance is strongly limited by the poor conductivity of $\mathrm{MnO}_{2}\left(10^{-5} \sim 10^{-6} \mathrm{~S}\right.$

$\mathrm{cm}^{-1}$ ). In addition, only the top layers of thick films of $\mathrm{MnO}_{2}$ is accessible to protons in the interface [41]. To date, there has been great interest in developing composites of $\mathrm{MnO}_{2}$ and porous carbon materials as substrate with a high surface area and good electrical conductivity [42]. 
Conducting polymers include polyaniline (PANI), polypyrrole (PPy) and so on. They have a high capacitance, good conductivity and low cost. The specific capacitance was reported to be more than $400 \mathrm{Fg}^{-1}$ [43]. However, electrodes of conducting polymers suffer poor cycling stability. Some considered that the mechanical stress on the electrodes caused swelling, shrinking and cracking of the polymer. In the same way as $\mathrm{MnO}_{2}$ incorporates with carbon substrate, the cycling stability of conducting polymers can be maintained by addition of carbon materials [44].

\subsection{Electrolyte}

Electrolyte is classified into two types: aqueous and organic electrolyte. Conductivity, operational potential window, corrosion are all critical factors to be considered in different electrode designs. Aqueous electrolytes possess advantages of a high conductivity $\left(0.8 \mathrm{Scm}^{-1}\right.$ for $\left.\mathrm{H}_{2} \mathrm{SO}_{4}\right)$ and low cost. According to thermodynamics, the potential window of aqueous electrolyte is relatively narrow (1.2 V). Organic electrolyte allows for higher voltage window above $2 \mathrm{~V}(2 \mathrm{~V} \sim 2.7 \mathrm{~V})$. The enlarged potential applied can improve the energy density due to the quadratic relation between potential and energy density (equation 2-3). Notable for organic electrolyte is a higher specific resistance compared to aqueous electrolyte (almost 20 50 times [45]). As a result, the higher resistance decreases specific power density (equation 2-4). 


\subsection{Evaluation of supercapacitor performance}

Quantitative testing methods for ECs primarily include cyclic voltammetry, charging/discharging test, electrochemical impedance spectroscopy and durability test. All the discussed electrochemical information such as resistance, capacitance, peak current, voltage window are determined by the structure, materials, stability of electrodes and electrolyte in specific designs.

\subsubsection{Cyclic voltammetry}

By loading a variable electrode potential linearly and cyclically versus time on the working electrode, the curve of the current versus the applied voltages is collected. An ideal capacitance exhibits a rectangle shape $\mathrm{CV}$ shape. The capacitance at a certain time/voltage is related with the charging current:

$$
\mathrm{C}=\frac{\mathrm{i}}{\mathrm{v}}
$$

Where $i$ is the capacitive charging current and $v$ is the scan rate in the experiment.

The capacitance can be calculated by equation [46]:

$$
C=\frac{\int i d U}{\Delta U v}
$$

Where $\Delta U$ is potential change across the cell.

\subsubsection{Constant current charge-discharge test}

Specific capacitance can also be estimated well from charge-discharge tests. When a constant current density $i$ is applied, a potential difference between two electrodes is developed. The capacitance can be calculated by equation: 


$$
C=\frac{i \Delta t}{\Delta U}
$$

An ideal capacitance exhibits skew lines in charge-discharge test. Generally, the potential of pseudopcapacitive process matches that of peak-current in CV curve.

\subsubsection{Electrochemical impedance spectroscopy}

Impedance measurement is useful to understand the electrochemical behavior of the electrode. In the Nyquist plot, an ideal capacitor exhibits a vertical line along the imaginary axis at lower frequency. For electrochemical capacitors, it turns to be a skew line with a finite slope resulted from Warbug impedance which is related with the mass transfer resistivity (distributed resistance/capacitance in a porous electrode). The capacitance can be estimated by equation [47]:

$$
C=-\frac{1}{2 \pi f z^{*}}
$$

\subsubsection{Durability Test}

EDLCs have potential to undergo for more than $10^{6}$ charge-discharge cycles without significant capacity loss. The excellent stability comes from the electrostatic charge storage principle and it gives supercapacitor great advantages over batteries. The cycle life and capacity retention ratio are important criteria for comparison of different electrode design for ECs. 


\section{References}

[1] "The electrical double layer". 23 April 2013.

[2] Becker, Howard I. "Low voltage electrolytic capacitor." U.S. Patent No. 2,800,616. 23 Jul. 1957.

[3] Conte, Mario. "Supercapacitors technical requirements for new applications." Fuel Cells 10 (2010): 806-818.

[4] Schindall, Joel. "The charge of the ultracapacitors." Spectrum, IEEE 44 (2007): 42-46.

[5] "Electric double-layer capacitors". ELNA. Retrieved 2015-02-21.

[6] Pandolfo, A. G., and A. F. Hollenkamp. "Carbon properties and their role in supercapacitors." Journal of power sources 157 (2006): 11-27.

[7] Conway, B. E. "Electrochemical supercapacitors: scientific fundamentals and technological applications, 1999." 1.

[8] Conway, B. E. (1991). "Transition from "supercapacitor" to "battery" behavior in electrochemical energy storage." Journal of the Electrochemical Society 138(6): 15391548.

[9] Conway, B. E., V. Birss, et al. (1997). "The role and utilization of pseudocapacitance for energy storage by supercapacitors." Journal of Power Sources 66(1-2): 1-14.

[10] Goodenough, John B., H. D. Abruna, and M. V. Buchanan. "Basic research needs for electrical energy storage." Report of the basic energy sciences workshop for electrical energy storage. Vol. 186. 2007.

[11] "NanoMarkets forecasts supercapacitor market to reach \$3B in 2016; decrease in transportation market share". Green Car Congress. 2010-11-21. Retrieved 2013-05-30. 
[12] Barbieri, O., et al. "Capacitance limits of high surface area activated carbons for double layer capacitors." Carbon 43 (2005): 1303-1310.

[13] Aricò, A. S., P. Bruce, et al. (2005). "Nanostructured materials for advanced energy conversion and storage devices." Nature Materials(4): 366-377.

[14] Frackowiak, E. and F. Beguin (2002). "Electrochemical storage of energy in carbon nanotubes and nanostructured carbons." Carbon 40(10): 1775-1787.

[15] Zhu, Yanwu, et al. "Carbon-based supercapacitors produced by activation of graphene." Science 332 (2011): 1537-1541.

[16] Zhi, Mingjia, et al. "Electrospun activated carbon nanofibers for supercapacitor electrodes." RSC Advances 4 (2014): 43619-43623.

[17] Wang, Da - Wei, et al. "3D aperiodic hierarchical porous graphitic carbon material for high - rate electrochemical capacitive energy storage." Angewandte Chemie 120 (2008): 379-382.

[18] Chen, Wei, et al. "High-performance nanostructured supercapacitors on a sponge." Nano letters 11 (2011): 5165-5172.

[19] Burke, Andrew. "R\&D considerations for the performance and application of electrochemical capacitors." Electrochimica Acta 53 (2007): 1083-1091. [20] Cooper, A., et al. "The ultrabattery-A new battery design for a new beginning in hybrid electric vehicle energy storage." Journal of Power Sources 188 (2009): 642-649. [21] Burke, Andrew, and Marshall Miller. "The power capability of ultracapacitors and lithium batteries for electric and hybrid vehicle applications." Journal of power sources 196 (2011): 514-522. 
[22] Wang, Yong-Gang, Zi-Dong Wang, and Yong-Yao Xia. "An asymmetric supercapacitor using $\mathrm{RuO}$ 2/TiO 2 nanotube composite and activated carbon electrodes." Electrochimica Acta 50 (2005): 5641-5646.

[23] Pandolfo, A.G.; Hollenkamp, A.F. (June 2006). "Carbon properties and their role in supercapacitors". J. Power Sources 157 (1): 11-27

[24] Namisnyk, Adam Marcus. A survey of electrochemical supercapacitor technology. Diss. University of Technology, Sydney, 2003. 21.

[25] Halper, Marin S., and James C. Ellenbogen. "Supercapacitors: A brief overview." The MITRE Corporation, McLean, Virginia, USA (2006): 1-34.

[26] Conway, B. E., V. Birss, and J. Wojtowicz. "The role and utilization of pseudocapacitance for energy storage by supercapacitors." Journal of Power Sources 66 (1997): 1-14.

[27] Burke, Andrew. "Ultracapacitors: why, how, and where is the technology." Journal of power sources 91 (2000): 37-50.

[28] Zhang, Jiujun, et al., eds. Electrochemical technologies for energy storage and conversion. John Wiley \& Sons, 2012.

[29] Pan, Hui, Jianyi Li, and Yuan Ping Feng. "Carbon nanotubes for supercapacitor." Nanoscale research letters 5 (2010): 654-668.

[30] Messaoudi, Bouzid, et al. "Anodic behaviour of manganese in alkaline medium." Electrochimica acta 46 (2001): 2487-2498.

[31] Du, B., et al. "Preparation of PPy/CNT composite applications for supercapacitor electrode material." Materials Science Forum. Vol. 610. 2009.

[32] Jurewicz, K., S. Delpeux, et al. (2001). "Supercapacitors from nanotubes/polypyrrole 
composites." Chemical Physics Letters 347(1-3): 36-40.

[33] Arbizzani, C., M. Mastragostino, et al. (2001). "New trends in electrochemical supercapacitors." Journal of Power Sources 100(1-2): 164-170.

[34] Frackowiak, E. and F. Beguin (2001). "Carbon materials for the electrochemical storage of energy in capacitors." Carbon 39(6): 937-950.

[35] Vix-Guterl, Cathie, et al. "Electrochemical energy storage in ordered porous carbon materials." Carbon 43 (2005): 1293-1302.

[36] Wang, Yan, et al. "Supercapacitor devices based on graphene materials." The Journal of Physical Chemistry C 113 (2009): 13103-13107.

[37] Yu, Aiping, et al. "Ultrathin, transparent, and flexible graphene films for supercapacitor application." Applied physics letters 96.25 (2010): 253105.

[38] Zhi, Mingjia, et al. "Nanostructured carbon-metal oxide composite electrodes for supercapacitors: a review." Nanoscale 5 (2013): 72-88.

[39] Zheng, J. P., P. J. Cygan, and T. R. Jow. "Hydrous ruthenium oxide as an electrode material for electrochemical capacitors." Journal of the Electrochemical Society 142 (1995): 2699-2703.

[40] Zhang, S. W., and G. Z. Chen. "Manganese oxide based materials for supercapacitors." Energy Materials 3 (2008): 186-200.

[41] Toupin, Mathieu, Thierry Brousse, and Daniel Bélanger. "Charge storage mechanism of $\mathrm{MnO} 2$ electrode used in aqueous electrochemical capacitor." Chemistry of Materials 16 (2004): 3184-3190. 
[42] Zhi, Mingjia, et al. "Highly conductive electrospun carbon nanofiber/MnO 2 coaxial nano-cables for high energy and power density supercapacitors." Journal of Power Sources 208 (2012): 345-353.

[43] Zhang, Kai, et al. "Graphene/polyaniline nanofiber composites as supercapacitor electrodes." Chemistry of Materials 22 (2010): 1392-1401.

[44] Yan, Jun, et al. "Preparation of graphene nanosheet/carbon nanotube/polyaniline composite as electrode material for supercapacitors." Journal of Power Sources 195 (2010): 3041-3045.

[45] Kötz, R., and M. Carlen. "Principles and applications of electrochemical capacitors." Electrochimica Acta 45 (2000): 2483-2498.

[46] Yan, Jun, et al. "Advanced asymmetric supercapacitors based on $\mathrm{Ni}(\mathrm{OH})$ 2/graphene and porous graphene electrodes with high energy density." Advanced Functional Materials 22 (2012): 2632-2641.

[47] Wang, Yong-Gang, Zi-Dong Wang, and Yong-Yao Xia. "An asymmetric supercapacitor using $\mathrm{RuO}$ 2/TiO 2 nanotube composite and activated carbon electrodes." Electrochimica Acta 50 (2005): 5641-5646. 


\section{Chapter 3 Hierarchically Porous Carbon Nanofiber as Flexible Electrode for \\ Symmetric Supercapacitor}

\subsection{Background and introduction}

Electrochemical double layer capacitors (EDLCs) possess unique characteristics such as high power density and ultrafast charge-discharge nature that are suitable in electric vehicles, power grid and pulse current supply applications $[1,2]$. The basic principle underlying in EDLCs is the accumulation of charges at the electrolyte/electrode interface. Several carbon materials, including carbon nanotubes (CNTs), graphene, mesoporous templated carbons, and carbon nanofibers are investigated due to their good physicochemical stability and electrical conductivity. In order to obtain high porosity and specific surface area that enhance the specific surface area of those carbon materials, various physical and chemical activation approaches were often employed. However, the narrow bottle-necks, random connections and the closure characteristic in activated carbons make a large portion of micropores inaccessible and retard the ion transport limiting the power density of EDLCs [3-6]. Hence, the energy storage performance can be enhanced by designing hierarchically porous carbons $[7,8]$, in which the macropores and mesopores in the carbon framework minimize the ion transport resistance and ion diffusion distance. Wu et al. fabricated three-dimensional graphene-based frameworks with macropores derived from hydrothermally assembled 3D graphene aerogels and mesopores generated by the silica networks, which showed a high specific capacitance of

$226 \mathrm{Fg}^{-1}[9]$. Another approach to fabricate hierarchically porous carbon is to generate porosity at gradient length scales in one simple step by template removal. Wang et al. 
reported on the fabrication of 3D aperiodic hierarchical porous graphitic carbon material featured macroporous cores, mesoporous walls and micropores using $\mathrm{Ni}(\mathrm{OH})_{2} / \mathrm{NiO}$ as template, which achieved high capacitance retention (90\%) at $100 \mathrm{mVs}^{-1}$ [10]. However, the electrode preparation remains very complicated in terms of the additional mass loading, homogeneity of binder and conductive agent.

Self-sustained and porous carbon nanofibers (CNFs) hold significant promise for efficient and high-energy-storage supercapacitors. Electrospinning is a simple and costeffective way to fabricate non-woven CNFs mats with high specific surface area and good conductivity [11]. Recent experiments have probed the electrochemical properties of porous CNFs by incorporation of other sacrificial agents with polyacrylonitrile (PAN) which is widely used as precursor due to its relatively high carbon yield [12] and good spinnability in solution $[13,14]$. Tran et al. electrospun PAN with sacrificial Nafion and obtained a high surface area $\left(1600 \mathrm{~m}^{2} \mathrm{~g}^{-1}\right)$ with large fraction of mesopores $(2-4 \mathrm{~nm})$ that showed a capacitance of $210 \mathrm{Fg}^{-1}$ in $1 \mathrm{M} \mathrm{H}_{2} \mathrm{SO}_{4}$ [15]. Kim et al. prepared porous CNFs using zinc chloride as sacrificial agent and achieved relatively high specific surface area $\left(550 \mathrm{~m}^{2} \mathrm{~g}^{-1}\right)$ and capacitance of $140 \mathrm{Fg}^{-1}$ in $6 \mathrm{M} \mathrm{KOH}$ solution [16].

In our approach, we show that flexible, self-sustained and hierarchically porous CNFs can be fabricated using terephthalic acid (PTA) as sacrificial agent. The nanofiber was obtained with an electrospinning technique, as shown in Figure 3-1. After sublimation and carbonization, the electrospun mat was converted to a hierarchically porous carbon framework. The key to this structure is that a macroporous network is distributed in the entire carbon nanofibers, while a highly hydrophilic surface is maintained so that the ions can access all the surface of CNFs. The porous carbon 
electrodes show a high specific capacitance of $231 \mathrm{Fg}^{-1}$ with good rate capability and excellent cycle performance.

\subsection{Experimental section}

\subsubsection{Electrode preparation}

0.9 g polyacrylonitrle (PAN) and $0.6 \mathrm{~g}$ terephthalic acid (PTA) were dissolved into $10 \mathrm{~g}$ Dimethylformamide (DMF) while stirring and heating at $85^{\circ} \mathrm{C}$ for $2 \mathrm{~h}$. The homogeneous precursor was put into a plastic syringe and the electrospinning was conducted in a homemade apparatus. The applied voltage was $15 \mathrm{kV}$ and the distance between the needle (25 gauge) and metal collector was $15 \mathrm{~cm}$. A constant feeding rate of

$0.5 \mathrm{mlL}^{-1}$ was used to supply the precursor. The as prepared fiber mats were first stabilized at $280^{\circ} \mathrm{C}$ in air at a heating rate of $1^{\circ} \mathrm{Cmin}^{-1}$. Then, it was carbonized in nitrogen at $800^{\circ} \mathrm{C}$ at a rate of $2^{\circ} \mathrm{Cmin}^{-1}$ and held at $800^{\circ} \mathrm{C}, 900^{\circ} \mathrm{C}$ or $1000^{\circ} \mathrm{C}$ for $2 \mathrm{~h}$, respectively. In order to make the carbon nanofiber hydrophilic, the CNFs were heating to $300^{\circ} \mathrm{C}$ in air for $1 \mathrm{~h}$. The as-prepared flexible carbon nanofibers were denoted as FCNF-800, FCNF-900 and FCNF-1000, respectively. Similarly, electrospun fiber from pure PAN precursor was stabilized at $280^{\circ} \mathrm{C}$ followed by carbonization at $900^{\circ} \mathrm{C}$ for $2 \mathrm{~h}$ and labeled as CNF-900.

\subsubsection{Characterization of the carbon fiber}

The morphology and structure of the carbon nanofibers were observed with a field-emission scanning electron microscope (FE-SEM) (JEOL 7600F) and a 
transmission electron microscope (TEM, JEOL JEM 2100F). The specific surface area and the pore size distribution of carbon nanofibers were measured by Nitrogen adsorption at $77 \mathrm{~K}$ with a Micromeritics ASAP 2020 system. The chemical status of elements was analyzed with X-ray photoelectron spectroscopy (XPS, PHI 5000 Versa Probe system, Physical Electronics). Nitrogen adsorption and desorption isotherms, specific surface area and pore size distribution of carbon nanofibers were measured using an ASAP 2020 instrument (Micromeritics inc.). The crystalline structure of the carbon nanofibers was characterized using a PANalytical X-ray diffraction (XRD) instrument (Cu k $\alpha$ source).

\subsubsection{Electrochemical testing}

The self-sustained carbon nanofibers were cut to $1 \mathrm{~cm} \times 1 \mathrm{~cm}$ pieces and the mass of each piece was about $3 \mathrm{mg}$. All the electrochemical data was collected with Solartron $1287 / 1260$ electrochemical system. For the three-electrode cell experiments, $\mathrm{Ag} / \mathrm{AgCl}$ was used as the reference electrode and $\mathrm{Pt}$ as the counter electrode in $6 \mathrm{M} \mathrm{KOH}$ aqueous electrolyte.

The symmetric two-electrode cell measurement was performed using a split test cell from MTI Corp (EQ-STC) with 6M KOH solution as electrolyte and a filter paper as separator. The potential sweep rates were from 10 to $200 \mathrm{mVs}^{-1}$ and the galvanostatic charge/discharge measurements were performed with current densities from $500 \mathrm{mAg}^{-1}$ to $20 \mathrm{Ag}^{-1}$. Nyquist plots were obtained in the frequency range from $100 \mathrm{kHz}$ to $0.01 \mathrm{~Hz}$ with an $\mathrm{AC}$ voltage of $10 \mathrm{mV}$ under open circuit conditions. The specific capacitance in the two-electrode cell can be calculated by the following equation:

$$
C=\frac{2 \times I \Delta t}{m \Delta V}
$$


Where $I$ is the current (A), $\Delta t$ is the discharging time, $m$ is the mass of the single electrode and $\Delta V$ is the voltage window. The energy density $E\left(\mathrm{Whkg}^{-1}\right)$ and power density $P\left(\mathrm{Wkg}^{-1}\right)$ were evaluated using the following equations:

$$
\begin{gathered}
E=\int(I * V * d t) /(2 m * 3.6) \\
P=\frac{3600 * E}{\Delta t}
\end{gathered}
$$

\subsection{Results and discussion}

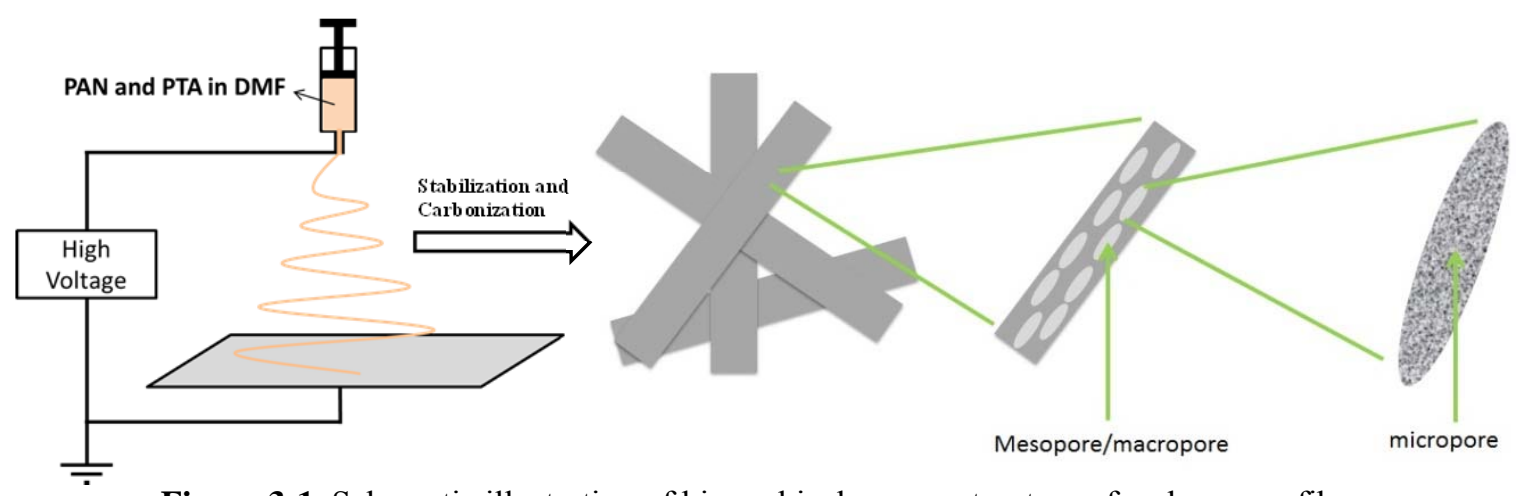

Figure 3-1 Schematic illustration of hierarchical porous structure of carbon nanofiber. 

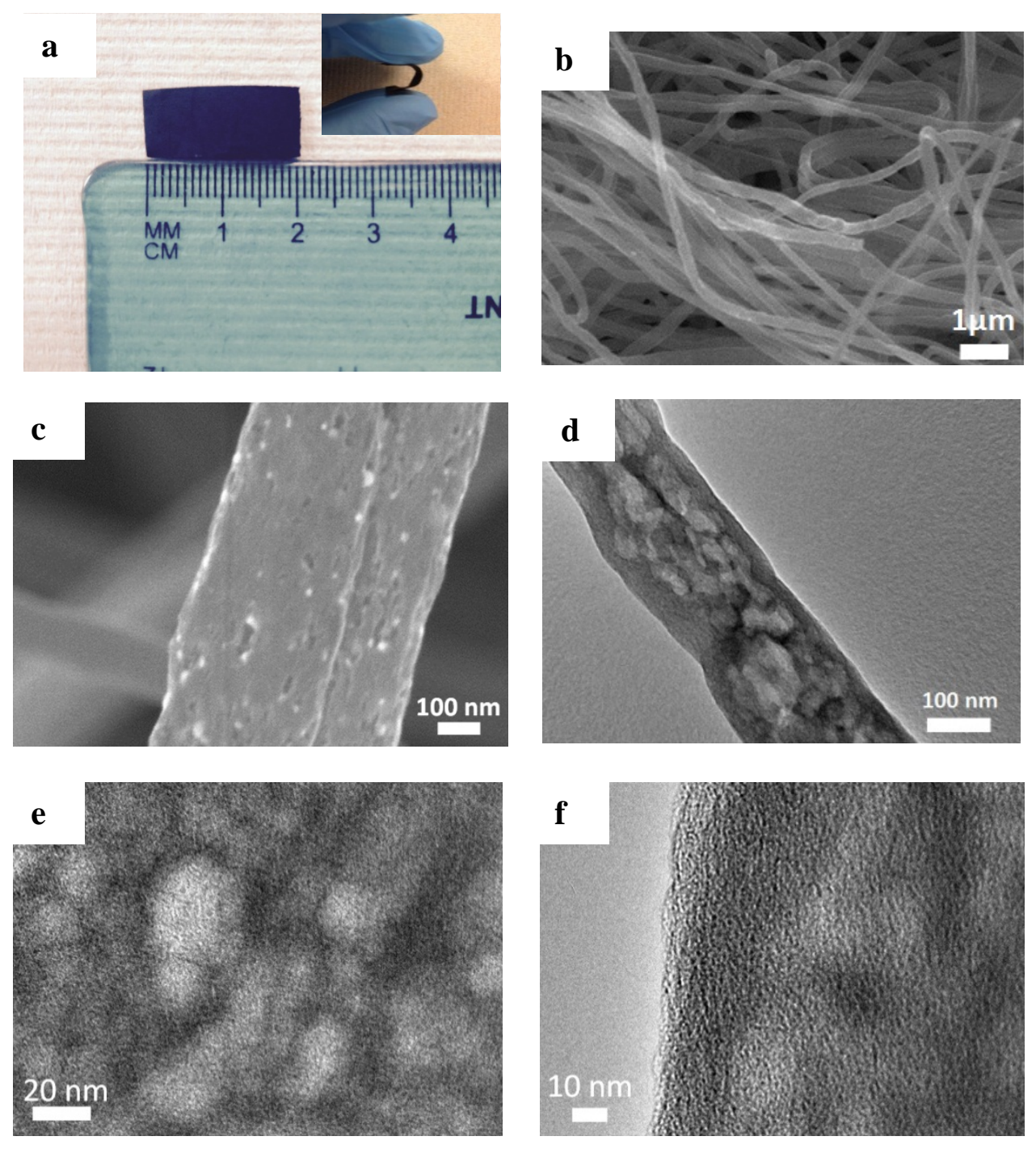

Figure 3-2 (a) Photograph of the flexible and hierarchical porous CNF. (b) SEM image of carbon nanofibers of sample FCNF-900. (c) SEM image of two parallel, round carbon nanofibers of sample FCNF900 with pores on surfaces. (d,e,f) TEM images of individual carbon nanofibers of sample FCNF-900. 

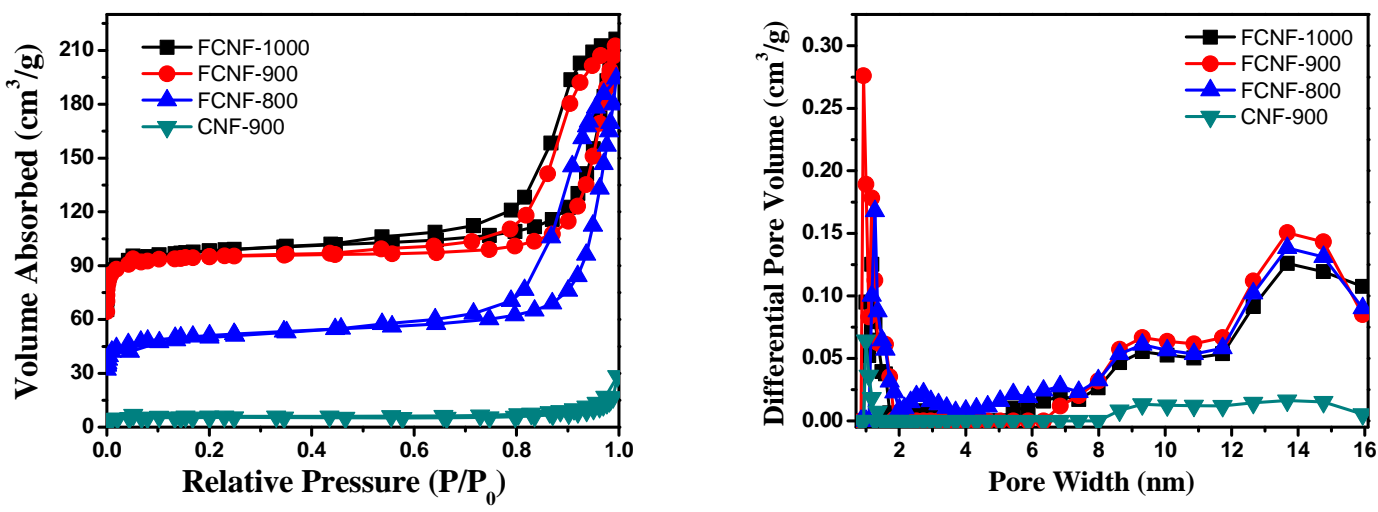

Figure 3-3 (a) $\mathrm{N}_{2}$ adsorption-desorption isotherm of carbon nanofibers.(b) density functional theory (DFT) pore size distribution

Table 3-1 Data summary of the $\mathrm{N}_{2}$ adsorption-desorption analysis for porous carbon nanofibers.

\begin{tabular}{ccccccc}
\hline & $\mathrm{S}_{\mathrm{BET}}\left(\mathrm{m}^{2} / \mathrm{g}\right)$ & $\mathrm{S}_{\text {micro }}\left(\mathrm{m}^{2} / \mathrm{g}\right)$ & $\mathrm{S}_{\text {meso\&macro }}\left(\mathrm{m}^{2} / \mathrm{g}\right)$ & $\mathrm{V}_{\text {total }}\left(\mathrm{cm}^{3} / \mathrm{g}\right)$ & $\mathrm{V}_{\text {micro }}\left(\mathrm{cm}^{3} / \mathrm{g}\right)$ & $\mathrm{Meso}-\&$ macropores $($ vol\%) \\
\hline FCNF-1000 & 331 & 278 & 53 & 0.31 & 0.13 & 57 \\
FCNF-900 & 319 & 281 & 37 & 0.31 & 0.13 & 57 \\
FCNF-800 & 174 & 124 & 49 & 0.26 & 0.06 & 77 \\
CNF-900 & 18 & 15 & 3 & 0.02 & 0.01 & 50 \\
\hline
\end{tabular}

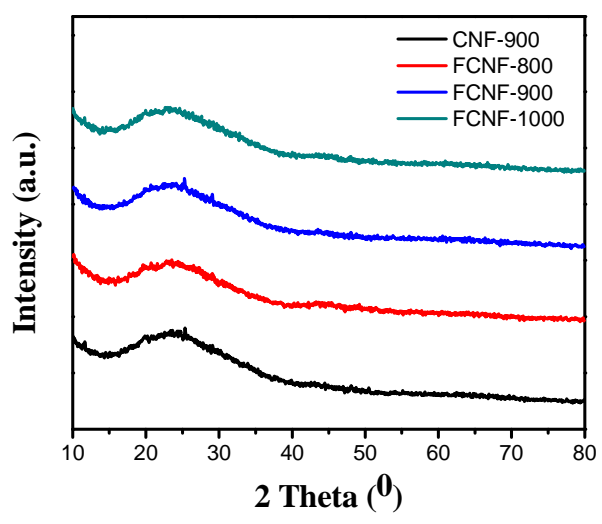

Figure 3-4 XRD patterns of carbon nanofibers.

The as-prepared FCNF exhibits excellent flexibility and the bending angle reaches $180^{\circ}$ as shown in Figure 3-2(a). Furthermore, it can also be folded to several layers and restored to the original state. The adorable flexibility was ascribed to the macropores 
which alleviate the strain across the fiber when force is loaded [17]. Figure 3-2 (b) shows the SEM image of the as-prepared carbon nanofibers of FCNF-900 after calcination with diameters around $200 \mathrm{~nm}$. A high-resolution SEM image (Figure 3-2 (c)) reveals a rough fiber surface with large mesopores/macropores randomly distributing across the carbon surfaces, which help accelerate ion transport since they could make high surface area contact of the inner structure of the fiber with electrolyte during electrochemical measurement. The large pores across the whole fiber surface are also examined by transmission electron microscopy (TEM). Figure 3-2 (d,e,f) clearly shows an interconnected porous structure of mesopores/macropores. These inner pores were created by the sublimation of terephthalic acid at around $402^{\circ} \mathrm{C}$ and those large pores on fiber surfaces were the outlets for the sublimated gas to exit.

Figure 3-3 (a) shows the nitrogen adsorption isotherms at $77 \mathrm{~K}$ of all samples. The isotherms of FCNF samples are type IV curves [18], indicating a micro-mesomacroporous characteristic. From the density function theory (DFT) pore size analysis, two regions can be observed in figure 3-3 (b) for all FCNF samples: micropores $(<2 \mathrm{~nm})$, mesopres $(2-16 \mathrm{~nm})$. Meanwhile, macropores $(>50 \mathrm{~nm})$ can be identified in the TEM images (Figure 3-3 (d)). The porosity properties of all samples are summarized in Table 3-1. The specific surface area (SSA) of FCNF samples has a tendency to increase with increasing carbonization temperature from 800 to $1000^{\circ} \mathrm{C}$. Both the specific volume and surface area of FCNF samples are much higher than those of CNF sample.

After carbonization at temperatures higher than $800^{\circ} \mathrm{C}$, the carbon nanofibers got graphite as shown as the bumps at around $25^{\circ}$ in XRD patterns for all nanofiber samples 
(Figure 3-4). The complete graphitization of carbon nanofibers ensures the high electrical conductivity as electrode materials.
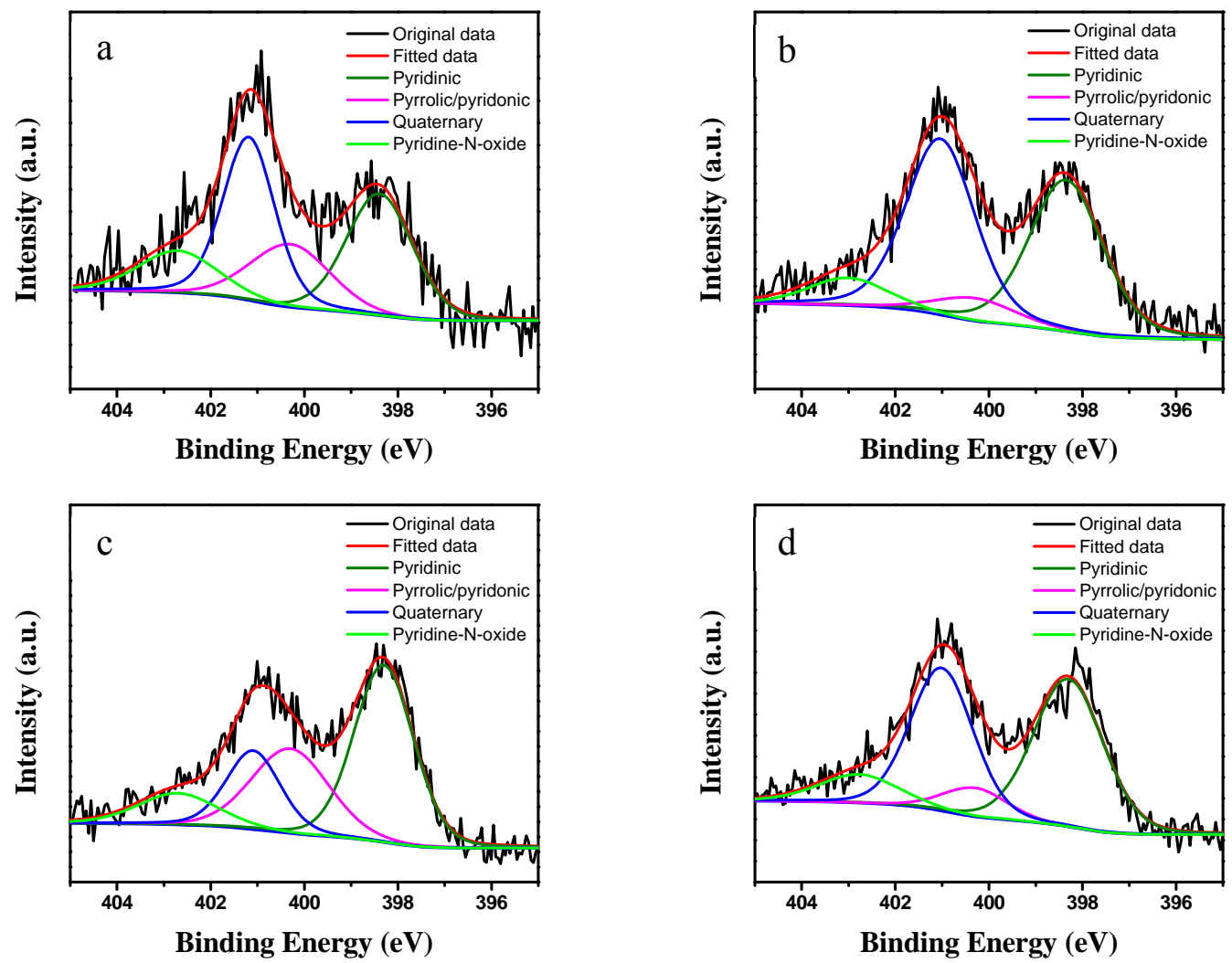

Figure 3-5 The detail scan of N1s of (a) FCNF-1000, (b) FCNF-900, (c) FCNF-800, (d) CNF-900

Table 3-2 XPS element composition of carbon nanofiber

\begin{tabular}{cccccccc}
\hline & $\begin{array}{r}\text { C1s } \\
\text { at.\% }\end{array}$ & $\begin{array}{c}\text { O1s } \\
\text { at.\% }\end{array}$ & $\begin{array}{c}\text { N1s } \\
\text { at.\% }\end{array}$ & $\begin{array}{r}\text { Pyridine-N-oxide } \\
\text { at.\% }\end{array}$ & $\begin{array}{r}\text { Quaternary } \\
\text { at.\% }\end{array}$ & $\begin{array}{r}\text { Pyrrolic/pyridonic } \\
\text { at.\% }\end{array}$ & $\begin{array}{c}\text { Pyridinic } \\
\text { at.\% }\end{array}$ \\
\hline FCNF-1000 & 88.4 & 5.0 & 6.6 & 0.9 & 2.3 & 1.3 & 2.1 \\
FCNF-900 & 85.5 & 6.0 & 8.5 & 0.7 & 3.9 & 0.4 & 3.5 \\
FCNF-800 & 81.4 & 5.5 & 13.1 & 1.4 & 2.4 & 3.6 & 5.7 \\
CNF-900 & 85.7 & 3.2 & 11.1 & 1.1 & 4.2 & 0.9 & 4.9 \\
\hline
\end{tabular}

XPS scans were taken for the samples to examine the surface compositions (Figure 3-5). Elements $\mathrm{C}, \mathrm{N}, \mathrm{O}$ are present in all the samples and the relative atomic concentrations are listed in Table 3-2. A gradual increase in carbon content was observed 
when carbonized the electrospun mats at higher temperatures. In contrast, the content of nitrogen content decreases significantly from $800^{\circ} \mathrm{C}$ to $1000^{\circ} \mathrm{C}$ while the content of oxygen is almost a constant. The intensity of the quaternary peak $(\sim 401.1 \mathrm{eV})$ become stronger than that of the pyridinic peak $(\sim 398.3 \mathrm{eV})$ as the carbonization temperature increased (Figure 3-5 (a, b, c)). The peaks at $403.0 \mathrm{eV}$ and $400.3 \mathrm{eV}$ are attributed to the pyridine-N-oxide and pyrrolic/pyridonic nitrogen, respectively.
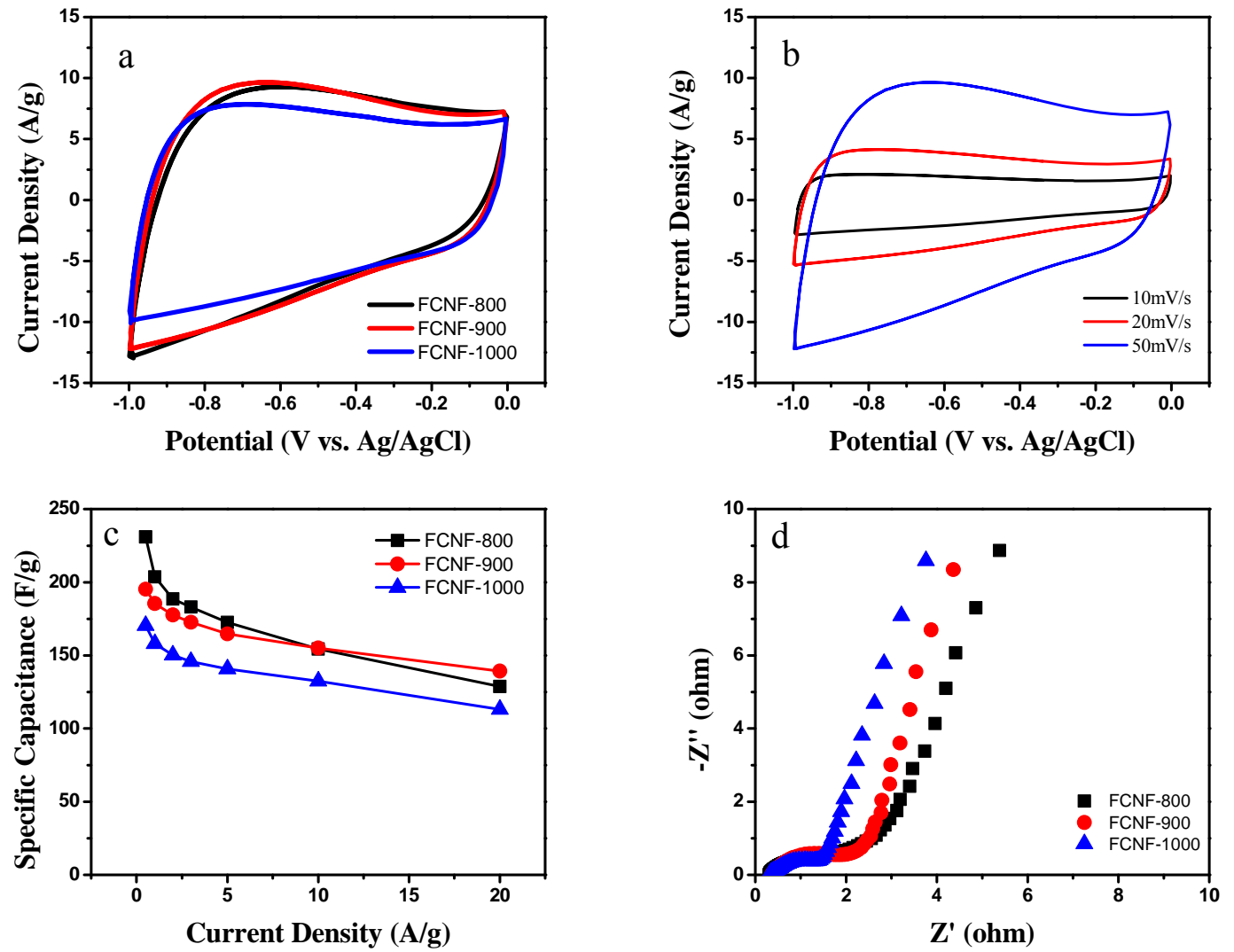

Figure 3-6 (a) Three-electrode CV curves of FCNF samples at a scan rate of $50 \mathrm{mVs}^{-1}$. (b) CV curves of FCNF-900 at different scan rates. (c) Specific capacitance of each sample at different current densities $(0.5$ $\left.\mathrm{Ag}^{-1}-20.0 \mathrm{Ag}^{-1}\right)$. (d) Nyquist plots of the FCNF samples. 
Figure 3-6 (a) compares the CV results of the flexible carbon nanofibers measured using a three-electrode cell system in $6 \mathrm{M} \mathrm{KOH}$ aqueous electrolyte. The current density of FCNF-900 is higher than the other two samples at relatively high scan rate $50 \mathrm{mVs}^{-1}$. Figure 3-6 (b) shows the CV curves of sample FCNF-900 at different scan rate from 10 $\mathrm{mVs}^{-1}$ to $50 \mathrm{mVs}^{-1}$. The $\mathrm{CV}$ curve shows nearly rectangular shape at different scan rates, indicating a good rate capability. FCNF-800 sample exhibited the highest specific capacitance value $\left(231 \mathrm{Fg}^{-1}\right)$ as compared with other nanofibers when charged at lower current density of $0.5 \mathrm{Ag}^{-1}$, which is probably attributed to rich nitrogen content (Figure 3-5). Hulicova-Jurcakova et al. reported that pyridinic nitrogen can enhance energy storage by inducing pseudocapacitance [19]. Although the content of pyridinic nitrogen functionality in CNF-900 is comparable to FCNF-800, the specific capacitance is the lowest in all the samples (Figure 3-6 (c)). The possible reason could be the poor accessibility of the large portion of surface area. Randomly distributed pores on the fiber surface of FCNF-900 as shown in Figure 3-1 (c) connect the inner surface area with the outer electrolyte. In addition, the macropores in the inner structure of carbon fiber can serve as "ion-buffering reservoirs" and the mesopores are the ion-transport pathway, which ultimately decrease the inner-pore resistance. The sharp drop of capacitance of FCNF-800 at higher charge current density is ascribed to the lower electrical conductivity, which is evidenced in EIS spectra in Figure 3-6 (d). In contrast, FCNF-900 maintains a better rate capability than FCNF-800 and exhibits the best capacitance value at high current density of $20 \mathrm{Ag}^{-1}$. Electrochemical impedance spectroscopy (EIS) is a useful characterization technique to investigate the kinetics of electrochemical processes at the interface of electrode/electrolyte. The semicircle diameter decreases to around 2 ohms 
representing a rapid charge transport in FCNF-900 and FCNF-1000 with increasing carbonization temperature (Figure 3-6 (d)). For an ideal capacitance, the EIS line becomes vertical to the $\mathrm{x}$-axis at lower frequency. The larger slope values representing Warburg impedance for FCNF-900 and FCNF-1000 reflect fast mass transfer rate in the pores of fiber. FCNF-900 displays a better capacitance at high current density than the other samples due to synergic advantages of additional pseudocapacitance from the nitrogen functional groups, fast ion-transport ascribed to a hierarchical porous structure and fast charge transfer enhanced by excellent electrical conductivity. Given the similar porous structure for both FCNF-900 and FCNF-1000 (BET in Figure 3-4 and Table 3-1), the descending performance in FCNF-1000 is mainly attributed to the loss of pyridinic nitrogen at higher temperature (XPS in Figure 3-5 and Table 3-2). 

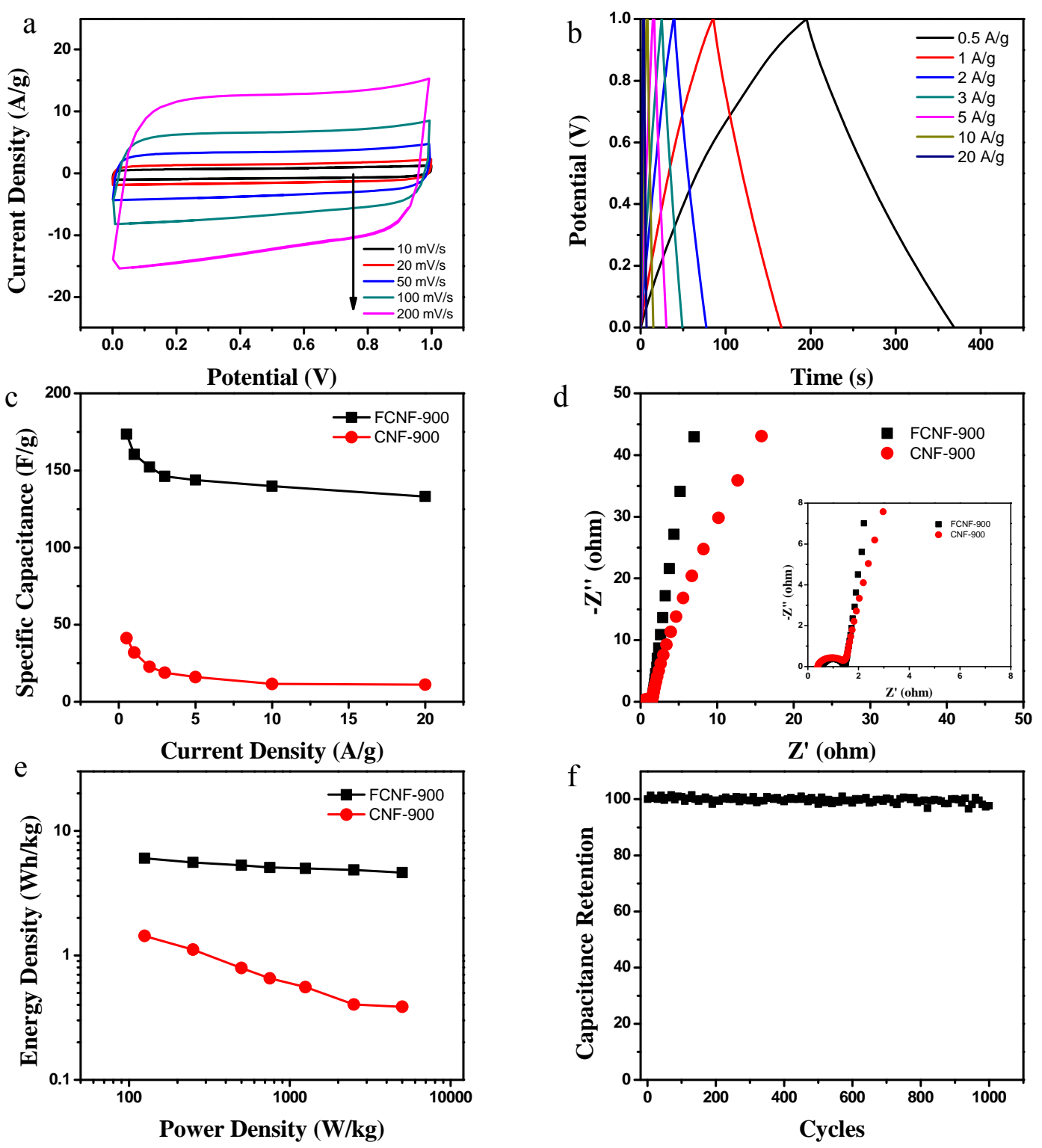

Figure 3-7 Electrochemical performance of FCNF-900 measured in a symmetric two-electrode system. (a) CV curves at different scan rates. (b) charge/discharge curves of FCNF-900 at different current densities. (c) specific capacitance at different current densities. (d) Nyquist plot.of the symmetric supercapacitor. (e) Ragone plot related to energy and power densities.(f) cycling stability at a current density of $10 \mathrm{Ag}^{-1}$.

The electrochemical performance of the optimized FCNF-900 was also evaluated by $\mathrm{CV}$ and charge/discharge measurements in a two-electrode cell. The scan rate for CV 
curve is from 10 to $200 \mathrm{mVs}^{-1}$ and the current density for galvanostatic charge/discharge is from $0.5 \mathrm{Ag}^{-1}$ to $20 \mathrm{Ag}^{-1}$. "Rectangular shape" of CV curves for all scan rates up to 200 $\mathrm{mVs}^{-1}$ represents an excellent rate capability. The specific capacitance is as high as 174 $\mathrm{Fg}^{-1}$ at $0.5 \mathrm{Ag}^{-1}$ and it reduces to $140 \mathrm{Fg}^{-1}$ at $20 \mathrm{Ag}^{-1}$ with a capacitance loss less than $30 \%$. In contrast, it was reported that commercial activated carbon AC suffers capacitance loss of more than $75 \%$ at high current density [20]. FCNF-900 maintains a symmetric triangular shape at each scan rate and a low IR drop is observed even at high current densities (Figure 3-7 (b)). The EIS shape of FCNF-900 in this two-electrode cell is similar to FCNF-900 in three-electrode measurement (Figure 3-6 (d)) indicating wellconstructed symmetric electrodes with the same mass and area. Furthermore, the equivalent series resistance (ESR) is only $0.5 \Omega$, which also contributes to a low IR drop.

Ragone plot provides the evaluation of energy and power density in energy storage devices (Figure 3-7(f)). The loss of energy density was small when the power density is high. At a current drain time of $7 \mathrm{~s}$, the energy and power densities are 4.9 $\mathrm{Whkg}^{-1}$ and $2500 \mathrm{Wkg}^{-1}$, respectively. This improved performance is associated with the unique hierarchical porous structure of FCNF-900. Both the outer fiber surface and innerporous structure can be accessible for charge accumulation along with the help of large pores on the surface. Macropores/mesopores in the fiber are also beneficial to accelerate the ion-diffusion into inner micropores.

Figure 3-7(f) shows the cycling stability of FCNF-900 in a two-electrode cell. The specific capacitance remains $97.6 \%$ of the initial value at $10 \mathrm{Ag}^{-1}$ after 1000 cycles indicating high reversibility of charge-discharge process on the surface of the electrodes. 


\subsection{Conclusions}

In summary, in the present work we present a flexible carbon nanofiber electrode with a unique hierarchical porous structure as an adorable supercapacitor. After the sublimation of sacrificial agent terephthalic acid, randomly distributed pores were created onto the fiber surface and macropores/mesopores were also developed resulting into an interconnected porous structure across the carbon nanofiber. Such hierarchical structure allows fast ion-diffusion into inner pores of fibers, therefore, enhances the accessible surface area for specific electrolyte ions. The specific capacitance reaches $174 \mathrm{Fg}^{-1}$ at 0.5 $\mathrm{Ag}^{-1}$ in two-electrode cell and preserves about $76 \%$ of capacitance at $20 \mathrm{Ag}^{-1}$. It's important to mention that the as-fabricated hierarchical porous structure could also serve as an ideal framework to further deposit active material coating on it like commonly used nickel foam. The porous structure in the fiber not only provides efficient pathways for ion and electron transport but allows more mass loading of active materials. Thus, the flexible carbon nanofibers are promising materials in developing energy storage devices with high performance.

\section{References}

[1] Korenblit, Yair, et al. "High-rate electrochemical capacitors based on ordered mesoporous silicon carbide-derived carbon."Acs Nano 4 (2010): 1337-1344. 
[2] Lee, Sang-Ick, et al. "Electric double-layer capacitance of microporous carbon nano spheres prepared through precipitation of aromatic resin pitch." Journal of power sources 139 (2005): 379-383.

[3] Liu, Hai - Jing, et al. "Ordered Hierarchical Mesoporous/Microporous Carbon Derived from Mesoporous Titanium - Carbide/Carbon Composites and its Electrochemical Performance in Supercapacitor." Advanced Energy Materials1 (2011): 1101-1108.

[4] Korenblit, Yair, et al. "High-rate electrochemical capacitors based on ordered mesoporous silicon carbide-derived carbon." Acs Nano 4 (2010): 1337-1344.

[5] Carriazo, Daniel, et al. "Block-copolymer assisted synthesis of hierarchical carbon monoliths suitable as supercapacitor electrodes." Journal of Materials Chemistry 20 (2010): 773-780.

[6] Liang, Yanyu, et al. "A simple approach towards one-dimensional mesoporous carbon with superior electrochemical capacitive activity." Chemical Communications 7 (2009): 809-811.

[7] Wang, Da - Wei, et al. "3D aperiodic hierarchical porous graphitic carbon material for high - rate electrochemical capacitive energy storage." Angewandte Chemie120 (2008): 379-382.

[8] Chen, Wei, et al. "High-performance nanostructured supercapacitors on a sponge." Nano letters 11 (2011): 5165-5172.

[9] Wu, Zhong-Shuai, et al. "Three-dimensional graphene-based macro-and mesoporous frameworks for high-performance electrochemical capacitive energy storage." Journal of the American Chemical Society 134 (2012): 19532-19535. 
[10] Wang, Da - Wei, et al. "3D aperiodic hierarchical porous graphitic carbon material for high - rate electrochemical capacitive energy storage." Angewandte Chemie120 (2008): 379-382.

[11] Kim, C., and K. S. Yang. "Electrochemical properties of carbon nanofiber web as an electrode for supercapacitor prepared by electrospinning." Applied Physics Letters 83 (2003): 1216-1218.

[12] J. B. Donnet, R. C. Bansal, Carbon Fibers, Marcel Dekker, New York 1990. [13] Zussman, Eyal, et al. "Electrospun Polyaniline/Poly (methyl methacrylate) Derived Turbostratic Carbon Micro - /Nanotubes." Advanced Materials 18 (2006): 348-353. [14] Li, Dan, and Younan Xia. "Electrospinning of nanofibers: reinventing the wheel?."Advanced materials 16 (2004): 1151-1170.

[15] Tran, Chau, and Vibha Kalra. "Fabrication of porous carbon nanofibers with adjustable pore sizes as electrodes for supercapacitors." Journal of Power Sources 235 (2013): 289-296.

[16] Kim, Chan, et al. "Self - Sustained Thin Webs Consisting of Porous Carbon Nanofibers for Supercapacitors via the Electrospinning of Polyacrylonitrile Solutions Containing Zinc Chloride." Advanced Materials 19 (2007): 2341-2346.

[17] Liu, Hua, et al. "Flexible macroporous carbon nanofiber film with high oil adsorption capacity." Journal of Materials Chemistry A 2 (2014): 3557-3562.

[18] Sing, Kenneth SW. "Reporting physisorption data for gas/solid systems with special reference to the determination of surface area and porosity (Recommendations 1984)." Pure and applied chemistry 57.4 (1985): 603-619. 
[19] Hulicova - Jurcakova, Denisa, et al. "Nitrogen - Enriched Nonporous Carbon

Electrodes with Extraordinary Supercapacitance." Advanced Functional Materials 19 (2009): 1800-1809.

[20] Ra, E. J., et al. "High power supercapacitors using polyacrylonitrile-based carbon nanofiber paper." Carbon 47 (2009): 2984-2992. 


\section{Chapter 4 Asymmetric Supercapacitors from Nano-architectured $\operatorname{LiMn}_{2} \mathrm{O}_{4} / /$ Activated Carbon Electrodes}

\subsection{Background and introduction}

The improvement of energy density of electrochemical capacitors (ECs) while maintaining high power density and long cycle-life is crucial for their successful applications in electric vehicles, portable electronics and renewable energy storage. Most commercial supercapacitors are developed using carbonaceous materials with a specific capacitance of $\sim 4 \mathrm{Fg}^{-1}$, a power density of $3 \sim 4 \mathrm{~kW} \mathrm{~kg}^{-1}$ and an energy density of $3 \sim 4 \mathrm{Wh}$ $\mathrm{kg}^{-1}[1]$. According to equation $\mathrm{E}=1 / 2 \mathrm{CV}^{2}$, the energy density can be raised by expanding the voltage window or improving the capacitance value. Developing asymmetric supercapacitor is an effective way to achieve high energy density. Pseudocapacitor electrodes which store charge via Faradaic process and usually possess greater capacitance than EDLCs [2-5]. Here, the asymmetric cell voltage can be higher than $\sim 1 \mathrm{~V}$ of EDLCs in aqueous electrolyte [6].

$\mathrm{LiMn}_{2} \mathrm{O}_{4}$ shows significant promise as cathode material and is currently the subject of intensive research owing to its low-cost, environmental safety and abundance in nature $[7,8]$. Many investigations have been made on the spinel $\mathrm{LiMn}_{2} \mathrm{O}_{4}$ with various morphologies such as nanoparticles [9], nanotubes [10,11], nanowires [12], nanorods [13], mesoporous structure [14], hollow micro/nanospheres [15,16], nanohybird material [17]. In these nanosized $\mathrm{LiMn}_{2} \mathrm{O}_{4}$ structures, short transport distance can facilitate lithium ion intercalation/deintercalation; large surface-to-volume ratio can increase electrodeelectrolyte interface. In particular, hollow structures among them can allow for strain 
relaxation in charging/discharging cycles $[11,16]$. Therefore, nano-architectured $\mathrm{LiMn}_{2} \mathrm{O}_{4}$ address capacity fading caused by structural transformation and achieve high power density due to fast lithium ion diffusion. Tang et al.[10] synthesized $\mathrm{LiMn}_{2} \mathrm{O}_{4}$ nanotube using carbon nanotube as template which delivers a high capacity at 6s-level charge rate without definite capacity loss after 1200 cycles. Ding et al.[16] also reported that doubleshelled hollow microspheres of $\mathrm{LiMn}_{2} \mathrm{O}_{4}$ prepared by a self-template $\left(\mathrm{MnCO}_{3}\right.$ microspheres) method exhibit a high capacity retention of $80 \%$ after 800 cycles at $5 \mathrm{C}$ rate.

In this work, we report a facile and cost-effective method to synthesis hollow $\mathrm{LiMn}_{2} \mathrm{O}_{4}$ nanosphere electrode using carbon black as template. This hollow $\mathrm{LiMn}_{2} \mathrm{O}_{4}$ nanospheres electrode exhibited a high specific capacitance of $311 \mathrm{Fg}^{-1}$ and excellent cycling stability. We fabricated an asymmetric supercapacitor using hollow $\mathrm{LiMn}_{2} \mathrm{O}_{4}$ nanosphere as the cathode and activated carbon as the anode working in $0.5 \mathrm{M} \mathrm{Li}_{2} \mathrm{SO}_{4}$ aqueous electrolyte. The asymmetric supercapacitor cell showed an energy density of $17.8 \mathrm{Wh} \mathrm{kg}^{-1}$ at a power density of $180 \mathrm{~W} \mathrm{~kg}^{-1}$.

\subsection{Experimental section}

\subsubsection{Electrode preparation}

$40 \mathrm{mg}$ of carbon black was dispersed in $50 \mathrm{~mL}$ of deionic water under sonication for $2 \mathrm{~h} .320 \mathrm{mg}$ of $\mathrm{KMnO}_{4}$ was dissolved in $150 \mathrm{~mL}$ of deionic water containing $0.1 \mathrm{~mL}$ concentrated $\mathrm{H}_{2} \mathrm{SO}_{4}(98 \mathrm{wt} \%)$. The carbon black suspension and the $\mathrm{KMnO}_{4}$ solution were mixed together following by heating in an oven at $85{ }^{\circ} \mathrm{C}$ until the solution color turned clear. The resulting precipitates were collected and washed with copious amounts 
of deionized water and dried at $60{ }^{\circ} \mathrm{C}$. The as-prepared powder was dispersed in deionic water. $17 \mathrm{mg}$ of $\mathrm{LiOH} \cdot \mathrm{H}_{2} \mathrm{O}$ was added under sonication for $1 \mathrm{~h}$. After that, the solution was stirred to evaporate water at room temperature. Then the mixture was collected and calcinated at $700{ }^{\circ} \mathrm{C}$ for $10 \mathrm{~h}$ in a tube furnace.

\subsubsection{Characterization}

The morphology and structure were observed with a field-emission scanning electron microscope (FE-SEM) (JEOL 7600F) and a transmission electron microscope (TEM, JEOL JEM 2100F). The chemical status of elements was analyzed with X-ray photoelectron spectroscopy (XPS, PHI 5000 Versa Probe system, Physical Electronics). The crystalline structure of the sample was characterized with a PANalytical X-ray diffraction (XRD) instrument ( $\mathrm{Cu}$ k $\alpha$ source).

\subsubsection{Electrochemical characterization}

Electrodes were prepared by mixing the as-prepared $\mathrm{LiMn}_{2} \mathrm{O}_{4}$ powder, carbon black and polyvinylidene fluoride with N-Methyl-2-pyrrolidone in a mass ratio of 75:20:5. The obtained slurry was pressed onto nickel foam and dried at $100{ }^{\circ} \mathrm{C}$ overnight. The mass loading of the active material was about $2.0 \mathrm{mg} \mathrm{cm}^{-1}$. Cyclic voltammetry (CV), galvanostatic charging/discharging, electrochemical impedance spectroscopy (EIS) were conducted in a Solartron 1287/1260 electrochemical system. The electrochemical performance was measured in aqueous electrolyte of $0.5 \mathrm{M} \mathrm{Li} \mathrm{Li}_{4}$ for both threeelectrode and two-electrode configurations. In the three-electrode system, $\mathrm{Ag} / \mathrm{AgCl}$ was use as reference electrode and Pt were used as counter electrode. In the asymmetric two- 
electrode configuration, $\mathrm{LiMn}_{2} \mathrm{O}_{4}$ was positive electrode and activated carbon (AC) was negative electrode and they are separated by a filter paper as separator. To achieve charge balance between these two electrodes in a full-cell, the mass ratio can be calculated by equation 4-1 [18]:

$$
\frac{m_{+}}{m_{-}}=\frac{C_{-} \times \Delta E_{-}}{C_{+} \times \Delta E_{+}} \quad \text { Equation 4-1 }
$$

\subsection{Results and discussion}

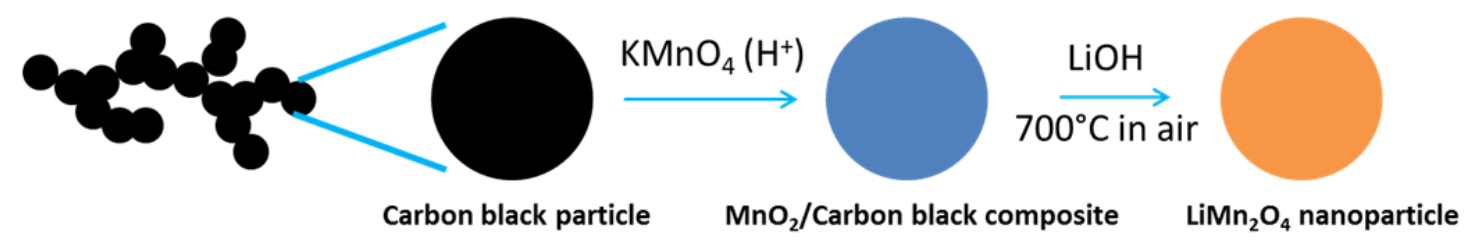

Figure 4-1 Schematic illustration of the synthesis of $\mathrm{LiMn}_{2} \mathrm{O}_{4}$ nanoparticle.
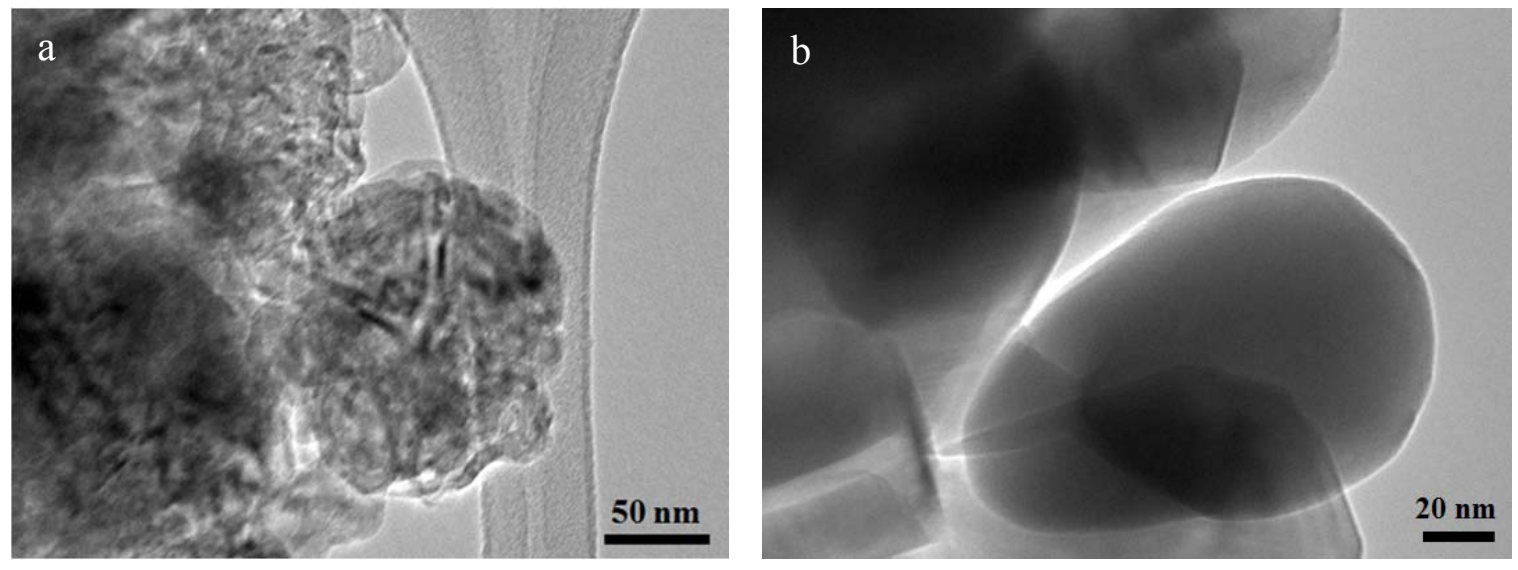

Figure 4-2 (a) TEM images of $\mathrm{MnO}_{2}$ /carbon composite, (b) TEM images of $\mathrm{LiMn}_{2} \mathrm{O}_{4}$ nanoparticle

The synthesis of the hollow $\mathrm{LiMn}_{2} \mathrm{O}_{4}$ nanospheres is schematically illustrated in Firgure 4-1. First, sacrificial carbon black substrate was converted to manganese dioxide 
coating in an acidic $\mathrm{KMnO}_{4}$ solution. The following calcination of the mixture at $700{ }^{\circ} \mathrm{C}$ in air burned off the remaining carbon black in the inner core and thus generated a $\mathrm{LiMn}_{2} \mathrm{O}_{4}$ nanoparticle structure. Figure 4-2 (a) shows TEM image of as-prepared $\mathrm{MnO}_{2}$ coating. The particle size of $\mathrm{MnO}_{2} /$ carbon composite is about $150 \mathrm{~nm}$ and needle-like $\mathrm{MnO}_{2}$ coating was distributed on the surface of carbon black substrate. The size of spinel $\mathrm{LiMn}_{2} \mathrm{O}_{4}$ nanoparticle is smaller than that of $\mathrm{MnO}_{2}$ due to the volume contraction during heat treatment.

Figure 4- (a) shows XRD patterns of $\mathrm{LiMn}_{2} \mathrm{O}_{4}$ nanoshell, which confirm the presence of spinel $\mathrm{LiMn}_{2} \mathrm{O}_{4}$ structure. Except $\mathrm{LiMn}_{2} \mathrm{O}_{4}$, there is also some minor impure phase $\mathrm{Mn}_{2} \mathrm{O}_{3}$ which is considered to be generated in lithium-deficiency area during heattreatment process ${ }^{1017}$. The surface compositions of the sample were examined by X-ray photoelectron spectroscopy (XPS) as shown in Figure 4-3 (b). Two main peaks can be observed in Mn 2p spectra: Mn 2 $\mathrm{p}_{3 / 2}$ and Mn 2 $\mathrm{p}_{1 / 2}$. The molar ratio of $\mathrm{Mn}^{3+}: \mathrm{Mn}^{4+}$ is 3:7.

a

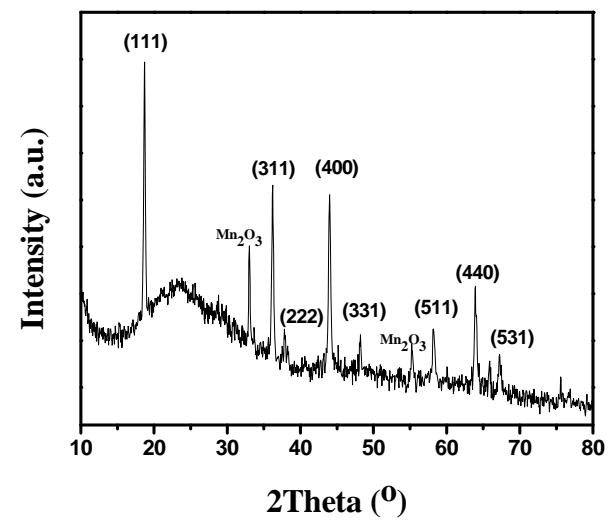

b

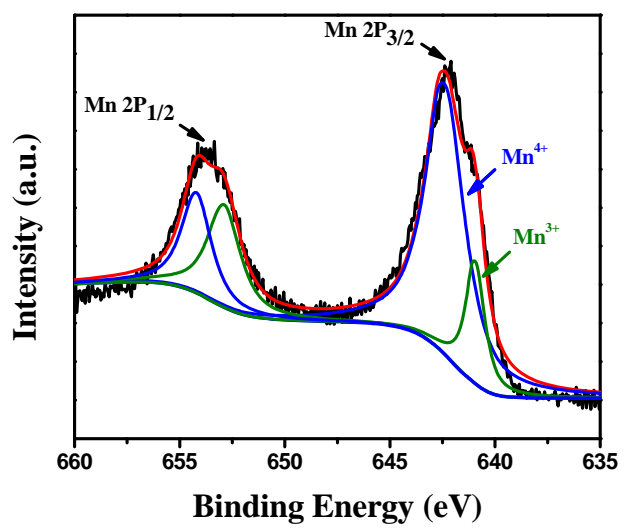

Figure 4-3 (a) XRD patterns of $\mathrm{LiMn}_{2} \mathrm{O}_{4}$ nanopartile, (b) $\mathrm{Mn} 2 \mathrm{p}$ spectra of $\mathrm{LiMn}_{2} \mathrm{O}_{4}$ nanoparticle. The black line represents the experimental data and the other lines are corresponding to the fitted data. 
a
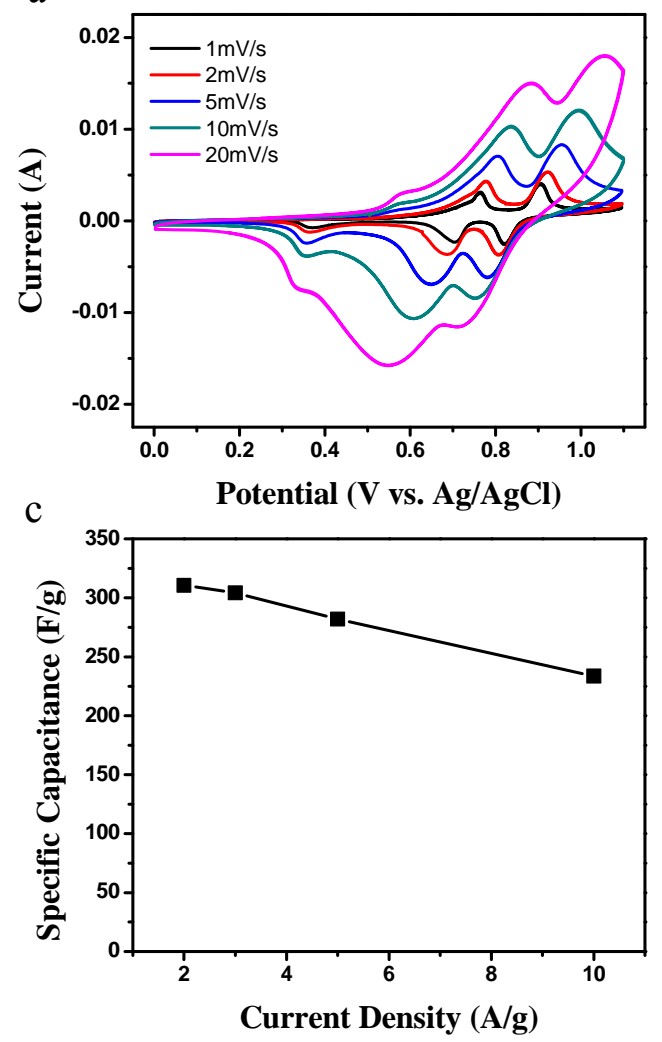

b

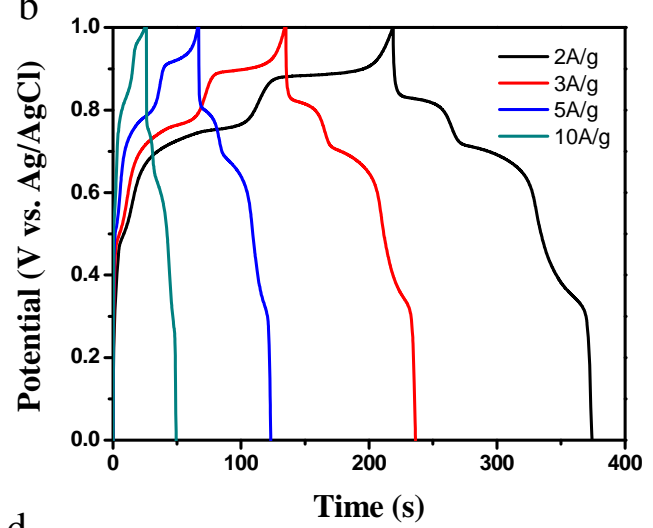

$\mathrm{d}$

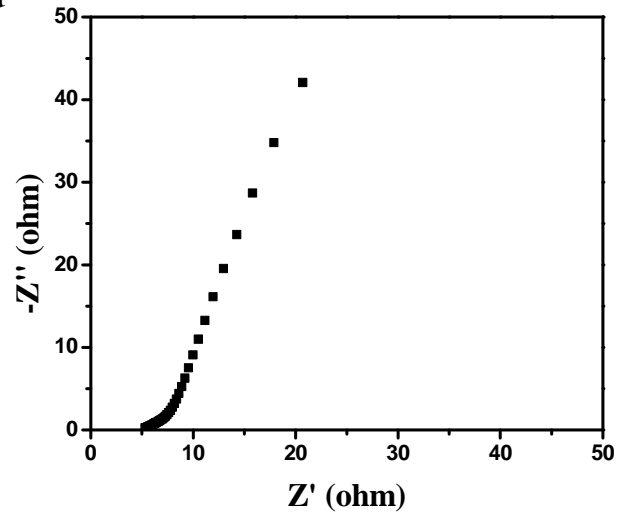

Figure 4-4 (a) $\mathrm{CV}$ curves of $\mathrm{LiMn}_{2} \mathrm{O}_{4}$ electrode at different scan rates, (b) charge-discharge curves of $\mathrm{LiMn}_{2} \mathrm{O}_{4}$ electrode at different current density, (c) specific capacitance of $\mathrm{LiMn}_{2} \mathrm{O}_{4}$ electrode, (d) Nyquist plot of $\mathrm{LiMn}_{2} \mathrm{O}_{4}$ electrode

The electrochemical performance of $\mathrm{LiMn}_{2} \mathrm{O}_{4}$ electrode was evaluated by $\mathrm{CV}$ and charge-discharge measurements in a three-electrode cell with $0.5 \mathrm{M} \mathrm{Li}_{2} \mathrm{SO}_{4}$ as electrolyte. Figure 4-4 (a) shows the $\mathrm{CV}$ curves of the $\mathrm{LiMn}_{2} \mathrm{O}_{4}$ electrode at different scan rates. Two pairs of strong redox peaks corresponding to spinel $\mathrm{LiMn}_{2} \mathrm{O}_{4}$ can be identified in the curves indicating that the mechanism of energy storage is mainly pseudocapacitance of spinel $\mathrm{LiMn}_{2} \mathrm{O}_{4}$. At a scan rate of $1 \mathrm{mVs}^{-1}$, the peak current potentials are $0.76 / 0.70 \mathrm{~V}$, $0.91 / 0.82 \mathrm{~V}$ respectively. The charge-discharge reactions involving lithium ion's insertion and extraction at these two pairs of potentials are shown in Equation 4-2 and Equation 4-3, respectively $[19,21]$ :

$$
\mathrm{LiMn}_{2} \mathrm{O}_{4} \rightleftharpoons \mathrm{Li}_{1-x} \mathrm{Mn} n_{2} \mathrm{O} 4+\mathrm{x} \mathrm{Li}^{+}+\mathrm{x} e^{-} \quad(0 \leq x \leq 0.5) \quad \text { Equation 4-2 }
$$




$$
\operatorname{LiMn}_{2} \mathrm{O}_{4} \rightleftharpoons \mathrm{Li}_{1-x} \mathrm{Mn}_{2} \mathrm{O} 4+\mathrm{x} i^{+}+\mathrm{x} e^{-} \quad(0.5 \leq x \leq 1) \quad \text { Equation 4-3 }
$$

The pair of weak redox peaks, appearing at 0.56 and $0.35 \mathrm{~V}$ for the anodic and cathodic peaks respectively, can be attributed to the minor phases of manganese dioxide [22]. Charging-discharging measurements were performed at various energy density of 2, 3, 5, $10 \mathrm{Ag}^{-1}$ (Figure 4-4 (b)). From the charging-discharging results, specific capacitances of the $\mathrm{LiMn}_{2} \mathrm{O}_{4}$ nanoparticles electrode at different current density are shown in Figure 4-4 (c). The electrode exhibits a high capacitance of $311 \mathrm{Fg}^{-1}$ and it retains $234 \mathrm{Fg}^{-1}$ at a high current density of $10 \mathrm{Ag}^{-1}$. The high capacity of energy storage can be attributed to the well-dispersed $\mathrm{LiMn}_{2} \mathrm{O}_{4}$ nanoparticle across the electrode. This structure facilitates the fast lithium intercalation and extraction in the spinel $\mathrm{LiMn}_{2} \mathrm{O}_{4}$. The Nyquist plot of the three electrode system is shown in Figure 4-4 (d). $\mathrm{LiMn}_{2} \mathrm{O}_{4}$ electrode in $0.5 \mathrm{M} \mathrm{Li}_{2} \mathrm{SO}_{4}$ has an equivalent series resistance (ESR) of about $5.3 \Omega$ suggesting a high charge-transfer rate at the electrode/electrolyte interfacial. 

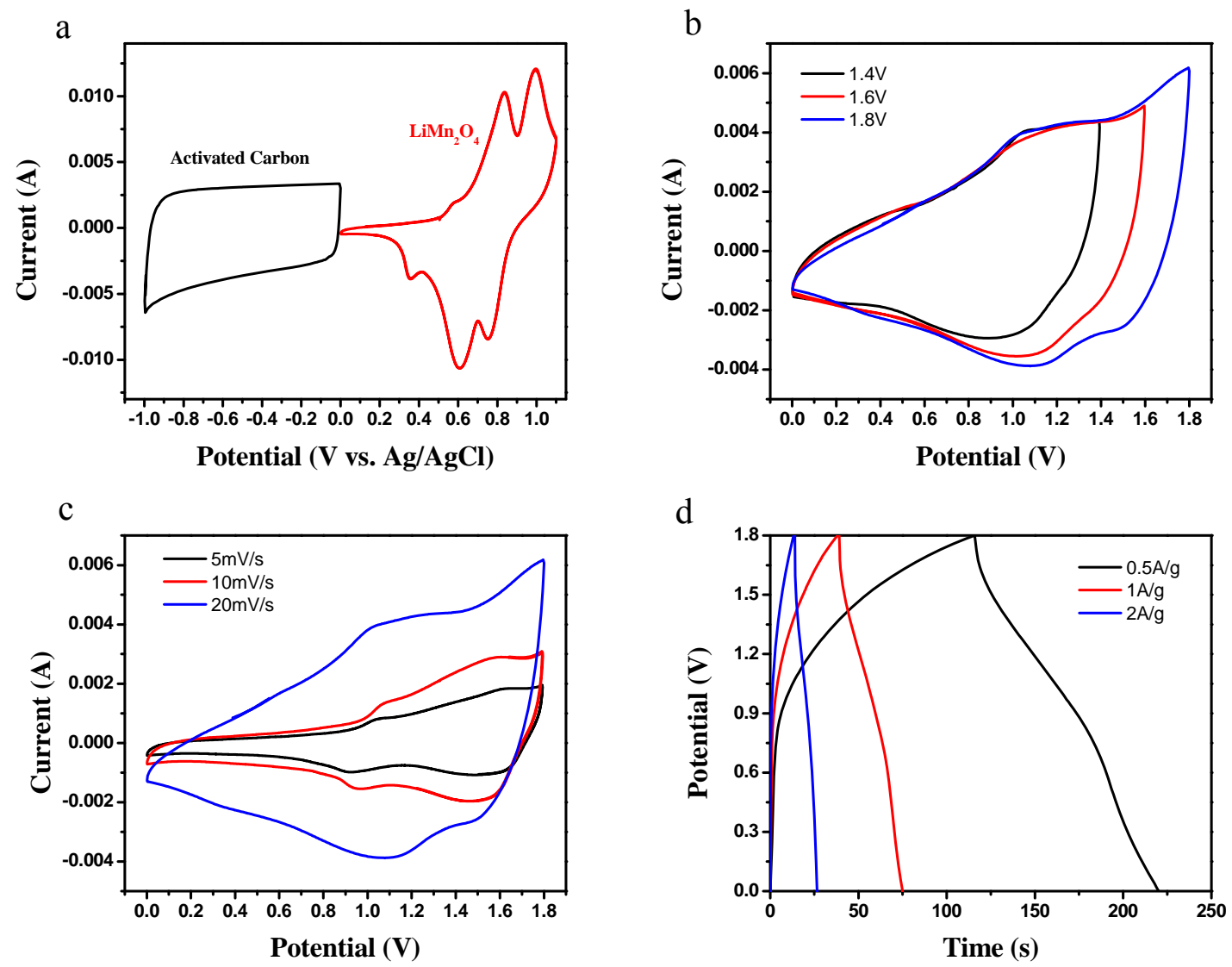

Figure 4-5 (a) Comparative CV curves of $\mathrm{LiMn}_{2} \mathrm{O}_{4}$ electrode and activated carbon (AC) electrode in a three-electrode configuration at $10 \mathrm{mVs}^{-1}$, (b) $\mathrm{CV}$ curves of $\mathrm{LiMn}_{2} \mathrm{O}_{4} / / \mathrm{AC}$ asymmetric supercapacitor performed at different potential window (scan rate: $50 \mathrm{mVs}^{-1}$ ), (c) $\mathrm{CV}$ curves of $\mathrm{LiMn}_{2} \mathrm{O}_{4} / / \mathrm{AC}$ supercapacitor at different scan rates, (d) galvanostatic charging-discharging curves of $\mathrm{LiMn}_{2} \mathrm{O}_{4} / / \mathrm{AC}$ supercapacitor at different current density.

Both CV curves of $\mathrm{LiMn}_{2} \mathrm{O}_{4}$ and activated carbon electrodes are shown in Figure 4-5 (a). These two electrode materials are stable in aqueous $0.5 \mathrm{M} \mathrm{Li}_{2} \mathrm{SO}_{4}$ electrolyte within different potential ranges which can be summed up to form a wide potential window in a full-cell.

A $\mathrm{LiMn}_{2} \mathrm{O}_{4} / / \mathrm{AC}$ asymmetric supercapacitor was developed to evaluate the capacitive performance in a full cell. The mass ratio of negative electrode to positive electrode is 3.2:1 according to Equation 4-1. As shown in Figure 4-5 (b), CV measurements were performed at different potential window to estimate the highest potential window applied in the full cell. Apparently, more redox peaks occur with an 
increase of the potential window from $1.4 \mathrm{~V}$ to $1.8 \mathrm{~V}$. At the highest operating potential $1.8 \mathrm{~V}$, both two pairs of redox peaks contributed by pseudocapacitance of positive electrode $\mathrm{LiMn}_{2} \mathrm{O}_{4}$ are present, promising a higher energy density according to equation $\mathrm{E}=1 / 2 \mathrm{CV}^{2}$. Figure $4-5$ (c) shows the $\mathrm{CV}$ measurements at different scan rates under the same potential window of $1.8 \mathrm{~V}$. All these $\mathrm{CV}$ curves exhibit potential-dependent currents at different scan rates which is different from carbon-based EDLC symmetric supercapacitors. The galvanostatic charging-discharging plots at different current densities are shown in Figure 4-4 (d).
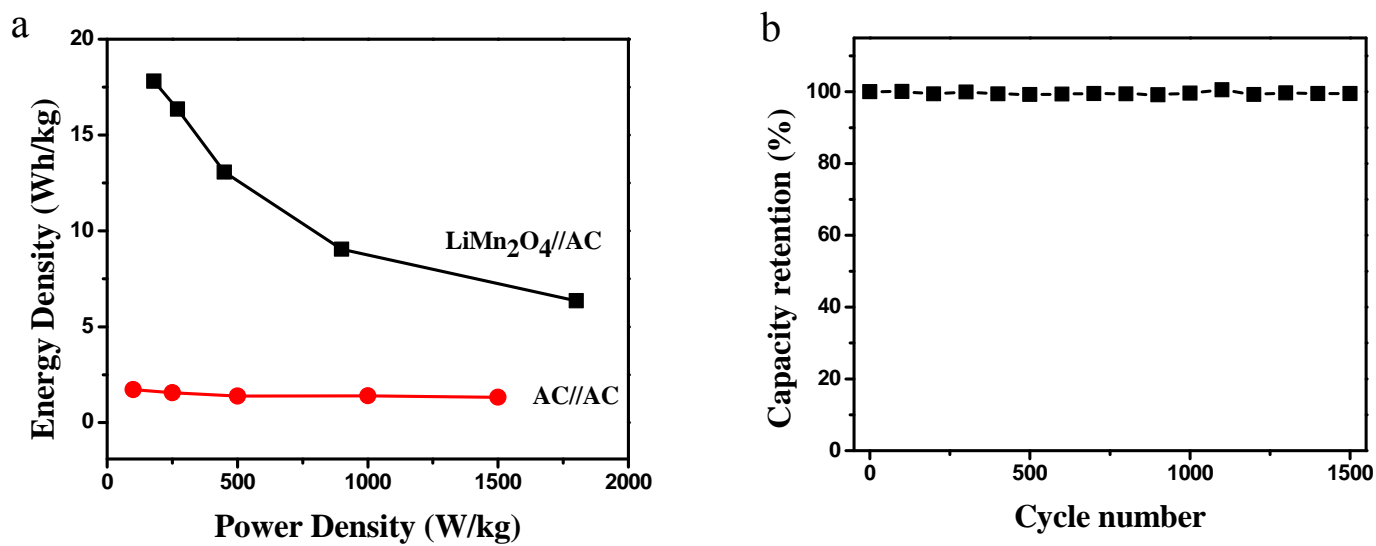

Figure 4-6 (a) Ragone plot of $\mathrm{LiMn}_{2} \mathrm{O}_{4} / / \mathrm{AC}$ asymmetric supercapacitor, (b) cycle performance of $\mathrm{LiMn}_{2} \mathrm{O}_{4} / / \mathrm{AC}$ asymmetric supercapacitor with a potential window of $1.8 \mathrm{~V}$ at current density of $10 \mathrm{Ag}^{-1}$ in $0.5 \mathrm{M} \mathrm{Li}_{2} \mathrm{SO}_{4}$ aqueous electrolyte.

Figure 4-6(a) presents the Ragone plot of the $\mathrm{LiMn}_{2} \mathrm{O}_{4} / / \mathrm{AC}$ asymmetric supercapacitor derived from the discharge curves at various charging-discharging current densities. The corresponding energy density reaches $17.8 \mathrm{Wh} \mathrm{kg}^{-1}$ when the power density is $180 \mathrm{Wkg}^{-1}$. The energy density is much higher than that of $\mathrm{AC} / / \mathrm{AC}$ symmetric supercapacitor at the same power density in $0.5 \mathrm{M} \mathrm{Li}_{2} \mathrm{SO}_{4}$ solution. The cycling stability is another requirement for supercapacitors. The cycle performance of $\mathrm{LiMn}_{2} \mathrm{O}_{4} / / \mathrm{AC}$ 
asymmetric supercapacitor was performed for 1500 cycles by repeating chargingdischarging between 0 and $1.8 \mathrm{~V}$ at $10 \mathrm{Ag}^{-1}$.Figure 4-6 (b) shows that this asymmetric cell exhibits excellent cycling stability without significant capacity loss after 1500 cycles.

\subsection{Conclusions}

In conclusion, $\mathrm{LiMn}_{2} \mathrm{O}_{4}$ nanoparticle was fabricated by a facile and cost-effective method using carbon black as sacrificial template. An asymmetric supercapacitor based on $\mathrm{LiMn}_{2} \mathrm{O}_{4}$ as positive electrode and activated carbon as negative electrode exhibits moderate energy density and excellent capacity retention in a cycling stability test. $\mathrm{LiMn}_{2} \mathrm{O}_{4}$-based asymmetric supercapacitor is a promising candidate for energy storage applications.

\section{References}

[1] Chen, Po-Chiang, et al. "Preparation and characterization of flexible asymmetric supercapacitors based on transition-metal-oxide nanowire/single-walled carbon nanotube hybrid thin-film electrodes." ACS nano 4 (2010): 4403-4411.

[2] Conway, Brian E. "Electrochemical Capacitors: Their Nature, Function, and Applications." Electrochemistry Encyclopedia (2003).

[3] Kim, I. H. and K. B. Kim (2001). "Ruthenium oxide thin film electrodes for supercapacitors." Electrochemical and Solid State Letters 4(5): A62-A64. 
[4] Mastragostino, M., C. Arbizzani, et al. (2001). "Polymer-based supercapacitors." Journal of Power Sources 97-8: 812-815.

[5] Ryu, K. S., K. M. Kim, et al. (2002). "Symmetric redox supercapacitor with conducting polyaniline electrodes." Journal of Power Sources 103(2): 305-309.

[6] Conway, B. E. "Electrochemical supercapacitors: scientific fundamentals and technological applications, 1999." 1.

[7] Aricò, Antonino Salvatore, et al. "Nanostructured materials for advanced energy conversion and storage devices." Nature materials 4 (2005): 366-377.

[8] Park, Ok Kyung, et al. "Who will drive electric vehicles, olivine or spinel?." Energy \& Environmental Science 4 (2011): 1621-1633.

[9] Curtis, Calvin J., Jiaxiong Wang, and Douglas L. Schulz. "Preparation and Characterization of $\mathrm{LiMn}_{2} \mathrm{O}_{4}$ Spinel Nanoparticles as Cathode Materials in Secondary Li Batteries." Journal of The Electrochemical Society 151 (2004): A590-A598. [10] Tang, Wei, et al. " $\mathrm{LiMn}_{2} \mathrm{O}_{4}$ nanotube as cathode material of second-level charge capability for aqueous rechargeable batteries." Nano letters 13 (2013): 2036-2040.

[11] Ding, Yuan - Li, et al. "Single - Crystalline $\mathrm{LiMn}_{2} \mathrm{O}_{4}$ Nanotubes Synthesized Via Template - Engaged Reaction as Cathodes for High - Power Lithium Ion Batteries." Advanced Functional Materials 21 (2011): 348-355.

[12] Hosono, Eiji, et al. "Synthesis of single crystalline spinel $\mathrm{LiMn}_{2} \mathrm{O}_{4}$ nanowires for a lithium ion battery with high power density." Nano letters 9 (2009): 1045-1051.

[13] Kim, Do Kyung, et al. "Spinel $\mathrm{LiMn}_{2} \mathrm{O}_{4}$ nanorods as lithium ion battery cathodes." Nano Letters 8 (2008): 3948-3952. 
[14] Jiao, Feng, et al. "Synthesis of ordered mesoporous $\mathrm{Li}-\mathrm{Mn}-\mathrm{O}$ spinel as a positive electrode for rechargeable lithium batteries." Angewandte Chemie International Edition 47 (2008): 9711-9716.

[15] Luo, Jia-Yan, Huan-Ming Xiong, and Yong-Yao Xia. "LiMn $2 \mathrm{O}_{4}$ nanorods, nanothorn microspheres, and hollow nanospheres as enhanced cathode materials of lithium ion battery." The Journal of Physical Chemistry C 112 (2008): 12051-12057. [16] Ding, Yuan-Li, et al. "Double-shelled hollow microspheres of $\mathrm{LiMn}_{2} \mathrm{O}_{4}$ for highperformance lithium ion batteries." Journal of Materials Chemistry 21 (2011): 9475-9479. [17] Wang, F. X., et al. "Spinel $\mathrm{LiMn}_{2} \mathrm{O}_{4}$ nanohybrid as high capacitance positive electrode material for supercapacitors." Journal of Power Sources 246 (2014): 19-23. [18] Khomenko, V., E. Raymundo-Pinero, and F. Béguin. "Optimisation of an asymmetric manganese oxide/activated carbon capacitor working at $2 \mathrm{~V}$ in aqueous medium." Journal of Power Sources 153 (2006): 183-190.

[19] Tarascon, J. Mrn, et al. "The Spinel Phase of $\mathrm{LiMn}_{2} \mathrm{O}_{4}$ as a Cathode in Secondary Lithium Cells." Journal of the Electrochemical Society 138 (1991): 2859-2864. [20] Thackeray, M. M., et al. "Lithium insertion into manganese spinels." Materials Research Bulletin 18 (1983): 461-472.

[21] Ohzuku, Tsutomu, Masaki Kitagawa, and Taketsugu Hirai. "Electrochemistry of Manganese Dioxide in Lithium Nonaqueous Cell III. X - Ray Diffractional Study on the Reduction of Spinel - Related Manganese Dioxide." Journal of The Electrochemical Society 137 (1990): 769-775. 
[22] Ghodbane, Ouassim, Jean-Louis Pascal, and Frédéric Favier. "Microstructural effects on charge-storage properties in $\mathrm{MnO}_{2}$-based electrochemical supercapacitors." ACS applied materials \& interfaces 1 (2009): 1130-1139. 


\section{Chapter 5 Lignin-derived Hierarchically Porous Carbon Prepared by a Self- assembly Method for Electrochemical Supercapacitor}

\subsection{Introduction}

Electrochemical double layer capacitors (EDLCs), with the features of high power density and excellent cycling stability, have a variety of applications in many fields including mobile devices, uninterruptable power supplies and electric vehicles. However, the energy density of EDLCs is low with a measured density of $5 \sim 10 \mathrm{Whg}^{-1}$, while it's 20 35 $\mathrm{Whkg}^{-1}$ for the lead acid batteries [1]. Ions in the electrolyte cross the pore space onto the surface of carbon by diffusion, but too small or tortuous micropores may hinder the ion transport. Although successful synthesis of mesoporsous carbon by template method and microporous carbon by alkali activation have been reported [2,3], the barrier of capacitance enhancement and supercapacitor application are situated deep in the synergistic effect among pores of multi-scales and cost of materials or preparation. The macropores are considered to be ion reservoirs to shorten diffusion distance. The mesopores are the ion transport passways to decrease resistance. The micropores can enhance the electric double layer adsorption. Hierarchically porous carbon has been proposed as a potential material for EDLCs and explored for years [4].

Self-assembly offers an alternative template strategy other than hard template method which requires multiple steps as well as corrosive hydrofluoric acid or strong potassium hydroxide. Organic-organic self-assembly method allows the direct formation of mesoporous polymer composite from carbon precursor and block copolymer, which can be converted to mesoporous carbon via carbonization. A variety of carbon precursors 
including phenol, resorcinol, phloroglucinol have been applied to prepare porous carbons. These organic precursors, however, may not be ideal for their fluctuation price. Utilizing low-cost natural product has been suggested as an effective way to meet continuous energy demands and enhance the recyclability of natural carbon sources.

Lignin, the major aromatic constituent of plants and wood [5], has recently been the focus of intense research activity [6-9]. With a variety of hydroxyl functional groups in the crosslinked macromolecular material, lignin show similar structure and reactivity as phenolic resin, which provides an attractive potential to replace phenolic resin in porous carbon synthesis. Breakthrough in lignin utilization will also convert it into valueadded products in papermaking and biorefinery industries.

Here, we report an organic-organic self-assembly method to prepare mesoporous lignin-char (MLC). We obtain - by creating additional nanoscale pores with alkali activation (KOH) in the mesoporous MLC-hierarchically porous carbon (HPC) with pores at different scale, as characterized by microscopy and Brunauer-Emmett-Teller (BET). We observed a significant effect of temperature and $\mathrm{KOH} / \mathrm{MLC}$ ration on the electrochemical performance. Appropriate pore size distribution can provide high power density and high energy density, combined with short diffusion distance and minimized the electric resistance. Through the investigation of porosity of the carbon electrode, we determined the optimized preparation conditions. The high performance of this biomass promised potential applications in low-cost supercapacitors devise. 


\subsection{Experimental section}

\subsubsection{Synthesis of lignin-derived hierarchically porous carbon}

Chemicals. Amphiphilic Block Copolymers Pluronic P123 (EO20-PO70-EO20), Lignin (alkali), were purchased from Sigma-Aldrich Inc. Formaldehyde solution $(37 \mathrm{wt} \%)$ were purchased from Macron Corp. Potassium hydroxide (95 100 wt\%)were purchased from BDH corp. Ethanol were supplied by Avantor corp. All reagents were used as received without any further purification. Deionized water was used in all of the experiments.

Synthesis. $1.0 \mathrm{~g}$ of lignin (alkali) in methanol $(4 \mathrm{~g})$ was stirred for $1 \mathrm{~h}$ and then P123 (1.0 g) dissolved in $5 \mathrm{~g}$ methanol was added dropwise under stirring. $1.8 \mathrm{~g}$ of formalin (37 wt \% formaldehyde), $1.0 \mathrm{~g}$ of methanol containing $1 \mathrm{mmol} \mathrm{HCl}$ were added dropwise, respectively. After further stirring for $12 \mathrm{~h}$ at room temperature, the final methanol solution was poured into dishes to evaporate methanol at room temperature for $8 \mathrm{~h}$ and kept in the oven at $100^{\circ} \mathrm{C}$ for $12 \mathrm{~h}$. Then, gel-like film was collected and ground into fine powder. The powder was transferred into a tube furnace and heat-treated to $700^{\circ} \mathrm{C}$ (heating rate: $1^{\circ} \mathrm{C} \min ^{-1}$ below $600^{\circ} \mathrm{C}$ and $2^{\circ} \mathrm{C} \min ^{-1}$ above $600^{\circ} \mathrm{C}$ ) and held at $700^{\circ} \mathrm{C}$ for $2 \mathrm{~h}$ in $\mathrm{N}_{2}$ atmosphere. The obtained char was sonicated in $6 \mathrm{M} \mathrm{HNO}$ for $2 \mathrm{~h}$ to remove the impurities and endow the surface with hydrophilic functional groups. After being washed and dried the mesoporous char was collected and labeled as MPC. The as-prepared MPC was mixed with $\mathrm{KOH}$ at weight ratio of $1: 3$ and heated to $700^{\circ} \mathrm{C}$ at a rate of $5^{\circ} \mathrm{C} \mathrm{min}^{-1}$ and held at $700^{\circ} \mathrm{C}$ for $1 \mathrm{~h}$ in $\mathrm{N}_{2}$ atmosphere. The product was washed in diluted $\mathrm{HCl}$ and deionized water repeatedly. The dried product is denoted as HPC. 


\subsubsection{Material characterization}

The morphology and structure of the samples were investigated with a fieldemission scanning electron microscope (FE-SEM) (JEOL 7600F) and a transmission electron microscope (TEM, JEOL JEM 2100F). Nitrogen adsorption measurements were carried out using a Micromeritics ASAP 2020 analyzer at $77 \mathrm{~K}$. The pore size distributions were obtained by density functional theory (DFT) in the software.

\subsubsection{Electrochemical testing}

The working electrode was prepared by mixing $90 \mathrm{wt} . \%$ of the as-prepared carbon materials and 10 wt.\% of polyvinylidene fluoride (PVDF) in N-methylpyrrolidinone (NMP) solvent. The slurry was pressed onto Nickel foam and dried at 100C overnight. The weight of active material was about $2 \mathrm{mg}$. The electrochemical measurements were performed on a Solartron 1287/1260 electrochemical system. In the three-electrode cell, $\mathrm{Ag} / \mathrm{AgCl}$ was used as reference electrode and $\mathrm{Pt}$ as the counter electrode in $6 \mathrm{M} \mathrm{KOH}$ aqueous solution. 


\subsection{Results and discussion}

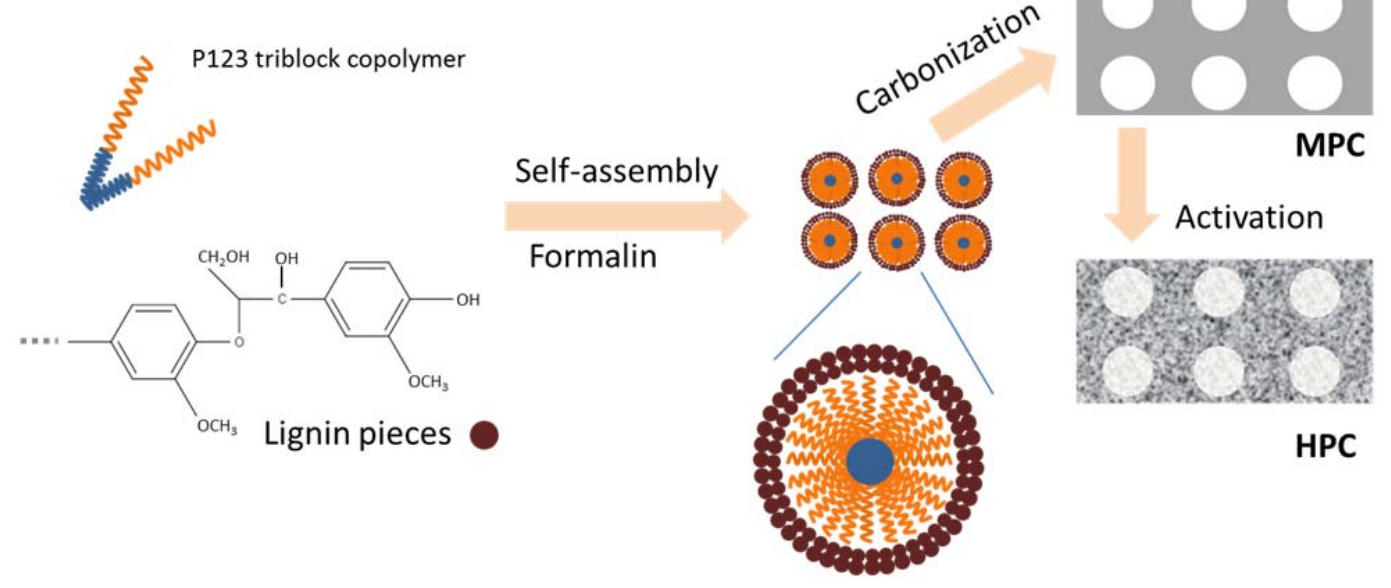

Figure 5-1 Schematic illustration of MPC and HPC fabrication

As shown in Figure 5-1, the synthesis procedure includes three major steps: organic-organic self-assembly, carbonization, and activation. The SEM and TEM images of MPC and HPC are shown in Figure 5-2. Rough surfaces are observed in both the SEM images of sample MPC and HPC (Figure 5-2 (a,b)). The TEM images (Figure 5-2 (c,d,e)) reveal the disordered mesopore structure which is expected to expedite the kinetics of ion diffusion [10]. Micropores around mesopores are visible in Figure 5-2 (f) due to alkali activation. 

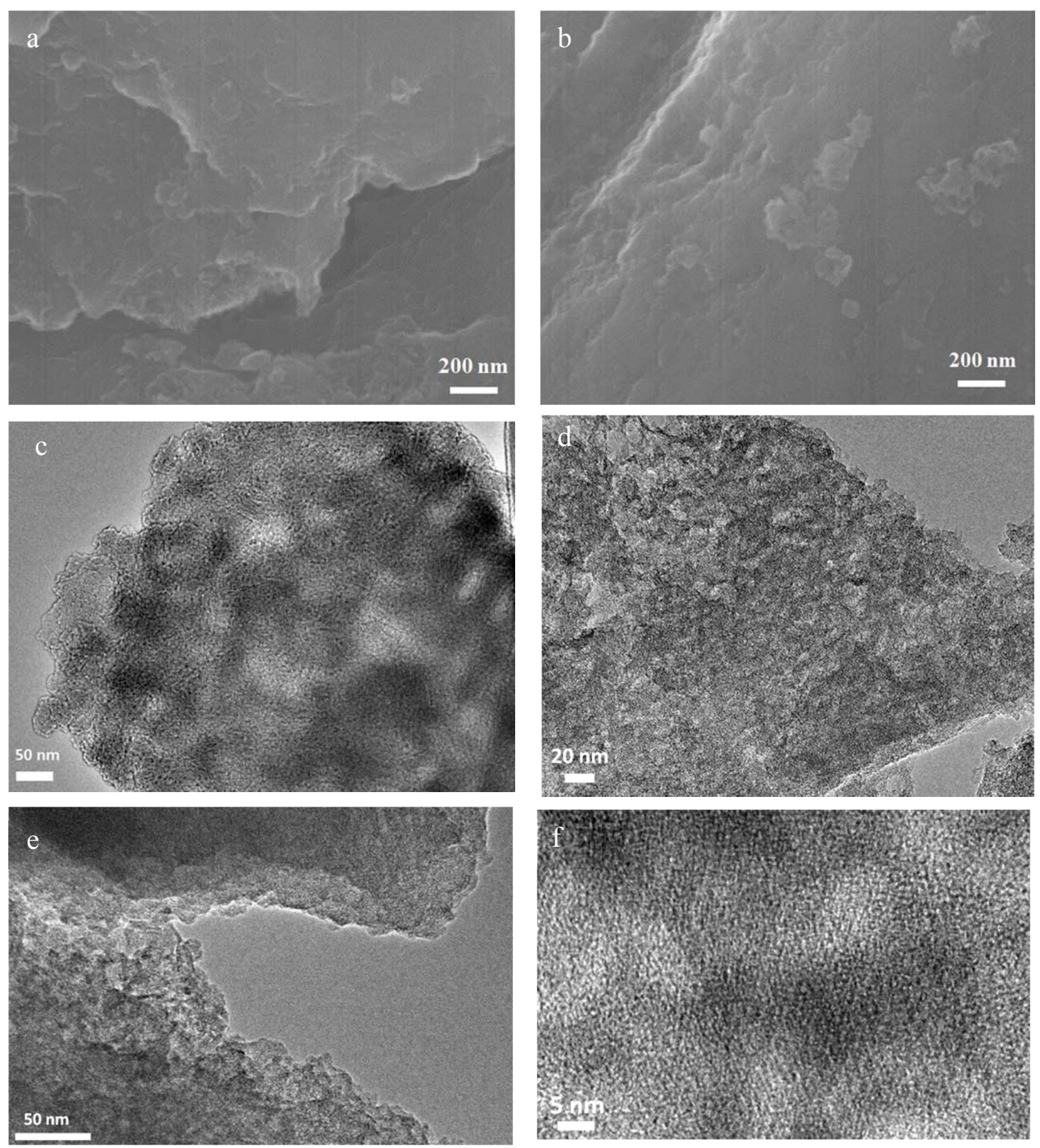

Figure 5-2 SEM images of sample (a) MPC, (b) HPC. TEM images of sample (c,e) MPC; $(d, f)$ HPC 
a

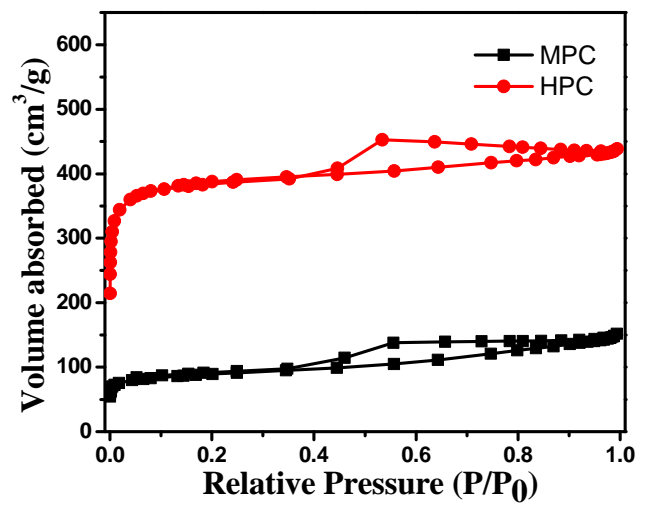

b

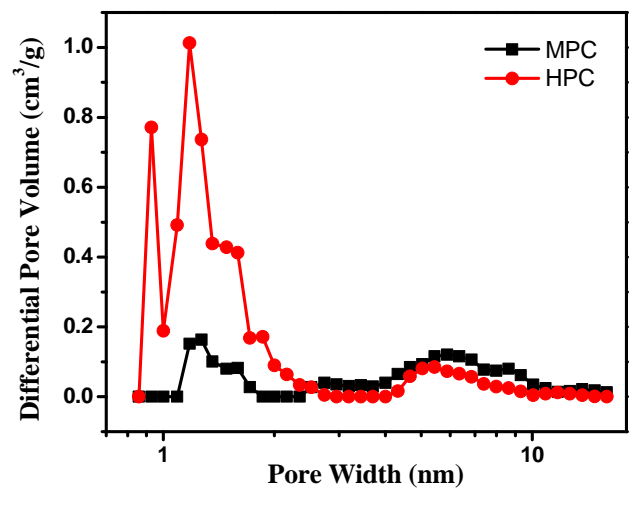

Figure 5-3 (a) Nitrogen sorption isotherms of sample MPC and HPC. (b) DFT Pore size distribution of sample MPC and HPC

Tabel 5-1 pore structure parameters of MPC and HPC

\begin{tabular}{ccccccc}
\hline & $\mathrm{S}_{\mathrm{BET}}\left(\mathrm{m}^{2} / \mathrm{g}\right)$ & $\mathrm{S}_{\text {micro }}\left(\mathrm{m}^{2} / \mathrm{g}\right)$ & $\mathrm{S}_{\text {meso }}\left(\mathrm{m}^{2} / \mathrm{g}\right)$ & $\mathrm{V}_{\text {total }}\left(\mathrm{cm}^{3} / \mathrm{g}\right)$ & $\mathrm{V}_{\text {micro }}\left(\mathrm{cm}^{3} / \mathrm{g}\right)$ & $\mathrm{V}_{\text {meso }}\left(\mathrm{cm}^{3} / \mathrm{g}\right)$ \\
\hline MPC & 305 & 194 & 111 & 0.23 & 0.09 & 0.14 \\
HPC & 1310 & 1082 & 228 & 0.67 & 0.50 & 0.17
\end{tabular}

$\mathrm{N}_{2}$ adsorption method is used to further characterize the porous structure of the as-prepared MPC and HPC. As shown in Figure 5-3, both isotherms are typical type IV curves with hysteresis loop closing at $\mathrm{P} / \mathrm{P}_{0} \sim 0.4$, indicating presence of mesopores, which is in agreement with the observation from SEM and TEM images. The pore size distribution curves illustrate hierarchically porous structures with micropores below $2 \mathrm{~nm}$ and mesopores above $2 \mathrm{~nm}$. The BET surface area and pore volume are calculated to be $305 \mathrm{~m}^{2} \mathrm{~g}^{-1}$ and $0.23 \mathrm{~cm}^{3} \mathrm{~g}^{-1}$, respectively with $61 \%$ mesoporosity. 

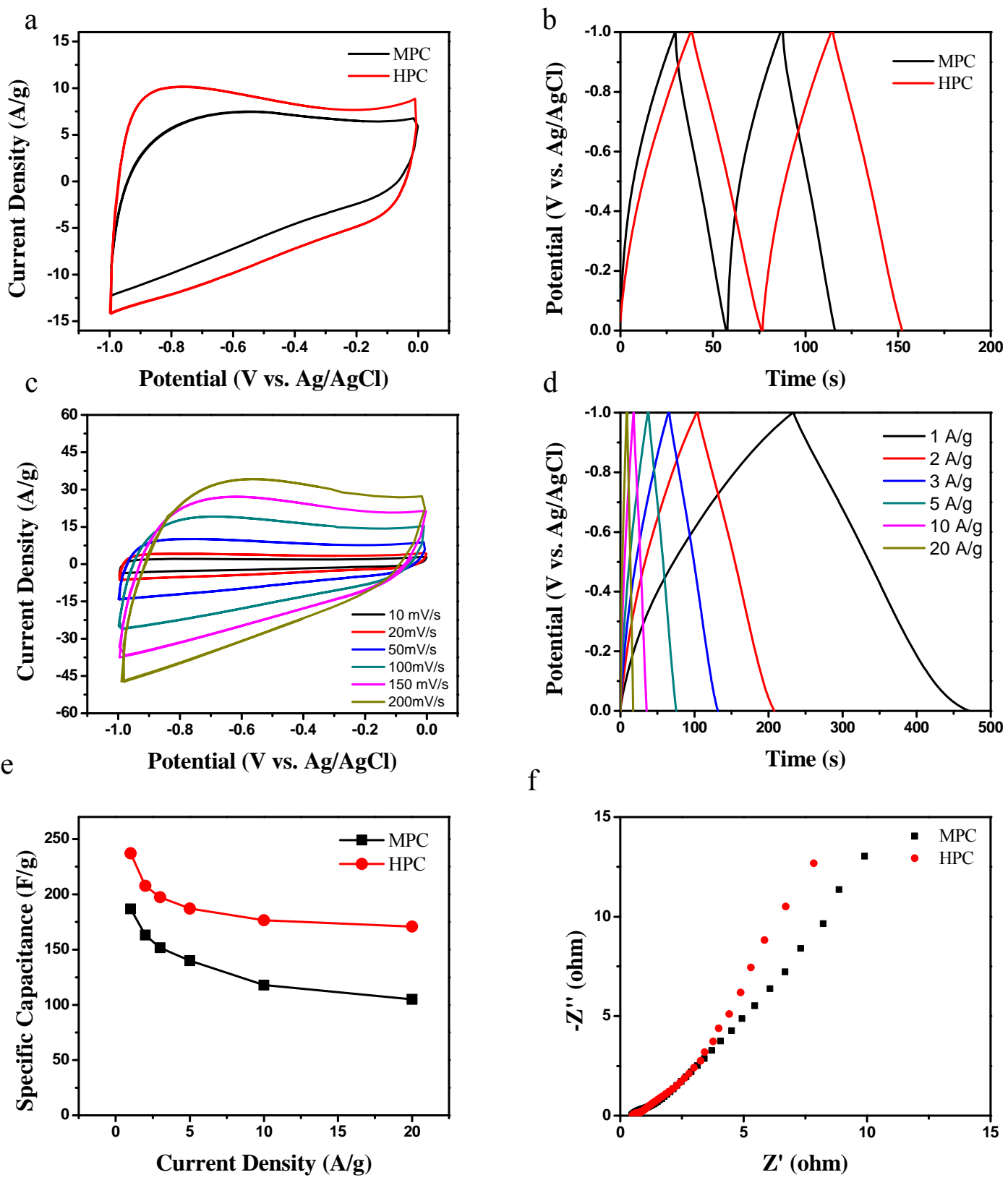

Figure 5-4 (a) Cyclic voltammograms of MPC and HPC at $50 \mathrm{mVs}^{-1}$; (b) galvanostatic charge/discharge curves of MPC and HPC at $5 \mathrm{Ag}^{-1}$; (c) Cyclic voltammograms of sample HPC at different scan rates; (d) charge-discharge curves of sample HPC at different current densities; (e) specific capacitances of sample MPC and HPC at different current densities; (f) Nyquist plots of samples MPC and HPC.

A series of electrochemical measurements were performed to evaluate the energy storage properties of the lignin-derived porous carbon materials. Figure 5-4 (a) demonstrates the comparative $\mathrm{CV}$ curves of MPC and $\mathrm{HPC}$ at a scan rate of $50 \mathrm{mVs}^{-1}$. 
Two curves exhibit quasi-rectangular shape indicating good capacitive behaviors. The galvanostatic charge-discharge curves of MPC and HPC at $5 \mathrm{Ag}^{-1}$ are shown in Figure 5-4 (b). Both curves are linear and symmetrical, which are consistent with quasi-capacitive performance in $\mathrm{CV}$ curves $\mathrm{CV}$ curves at various scan rates and galvanostatic chargedischarge curves for various current densities are presented in Figure 5-4 (d) and (e), respectively. All the CV curves in Figure 5-4 (d) exhibit quasi-rectangular shapes and all the charge-discharge curves are nearly linear and symmetrical, indicating the capacitive behaviors are well kept even at high scan rates and current densities. The specific capacitances at different current density are plotted in Figure 5-4 (e). The highest values of samples MPC and HPC are $187 \mathrm{Fg}^{-1}$ and $237 \mathrm{Fg}^{-1}$, respectively, at a current density of $1 \mathrm{Ag}^{-1}$. The specific capacitance of HPC decreases slowly with increasing current density and still keep $171 \mathrm{Fg}^{-1}$ at the high current density of $20 \mathrm{Ag}^{-1}$, which is $72 \%$ of the specific capacitance at $1 \mathrm{Ag}^{-1}$. The good rate capability indicates rapid ion transport which may arise from its unique hierarchically porous structure. Apparently, HPC possesses higher capacitance than MPC determined either in CV curves or galvanostatic charge/discharge measurements (Figrue 5-4 (a) and (b)). The better performance of the HPC can be attributed to more micropores generated in activation compared with MPC. It's considered that both micro- and mesopores are of significance in developing highcapacitance materials [11,12], thus a balance between micropores and mesopres is critical for achieving high energy density and power density [13].

Figure 5-4 (f) shows the Nyquist plot of MPC and HPC at a perturbative amplitude of $10 \mathrm{mV}$. The curve slope of HPC is larger than that of MPC, indicating a 
better capacitor behavior. Minor semicircles at high frequency region of both MPC and HPC represent low charge-transfer resistances at the electrode/electrolyte interface.

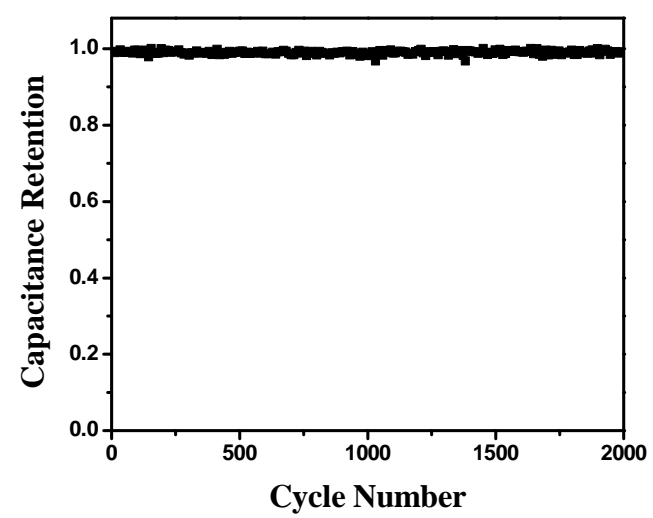

Figure 5-5 Cycle performance of $\mathrm{HPC}$ in $6 \mathrm{M} \mathrm{KOH}$ aqueous solution at current density of $10 \mathrm{Ag}^{-1}$.

Figure 5-5 shows the cycling performance of HPC in the three-electrode configuration. The sample HPC retains $99 \%$ of its initial capacitance after 2000 cycles. The HPC electrode displays excellent cycling stability guarantees its practical application requiring long-term service. 

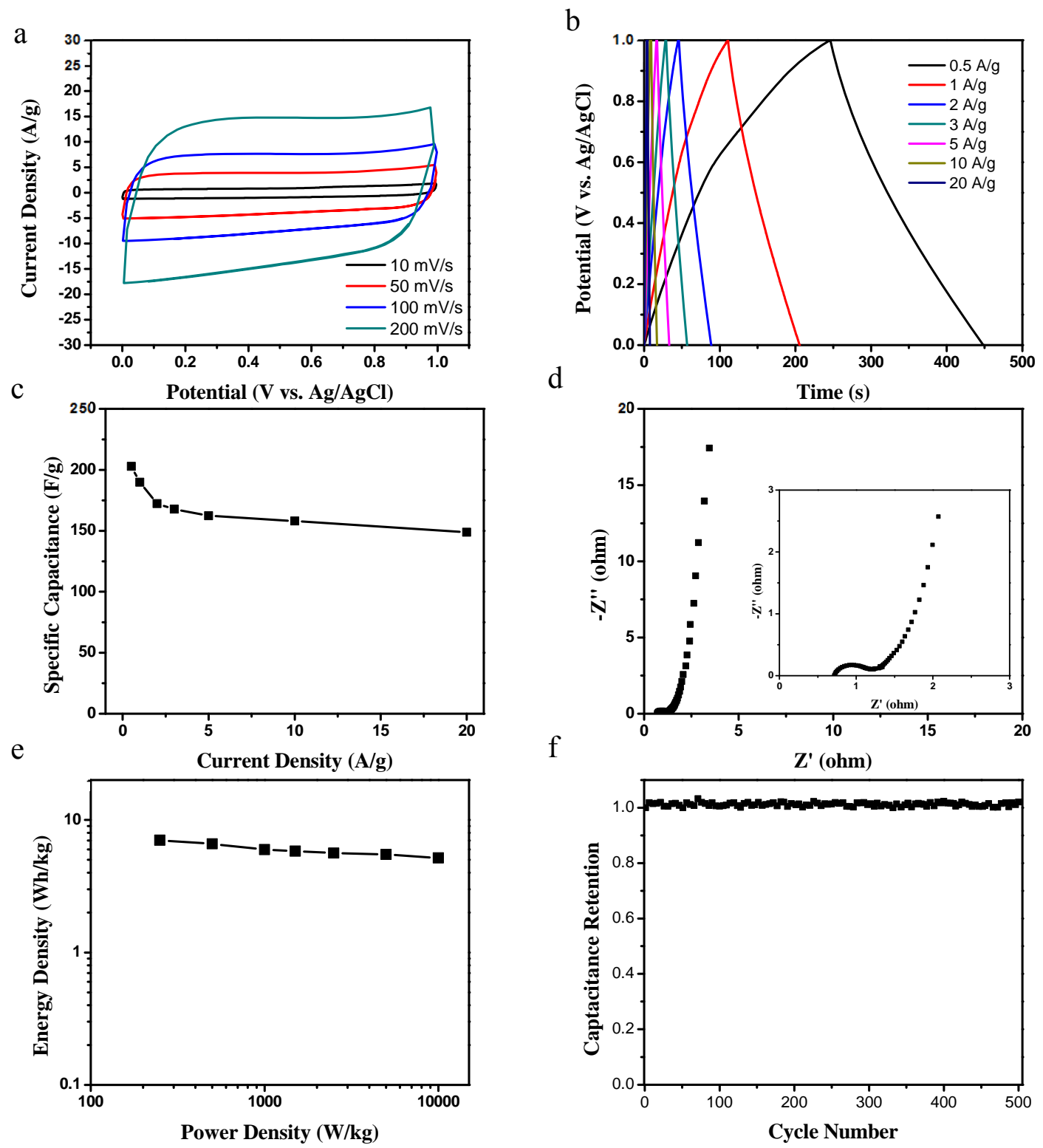

Figure 5-6 Electrochemical performance of HPC measured in a symmetric two-electrode system. (a) CV curves at different scan rates. (b) charge/discharge curves of HPC at different current densities. (c) specific capacitance at different current densities. (d) Nyquist plot.of the symmetric supercapacitor. (e) Ragone plot related to energy and power densities.(f) cycling stability at a current density of $5 \mathrm{Ag}^{-1}$. 


\subsection{Conclusions}

In summary, we successfully synthesized lignin-derived hierarchically porous carbons through an organic-organic self-assembly method. The unique hierarchically porous structure can help to minimize the electrical resistance and expedite ion transport. The obtained carbon electrodes MPC and HPC exhibit high capacitances of $187 \mathrm{Fg}^{-1}$ and $237 \mathrm{Fg}^{-1}$, respectively. Furthermore, less than $1 \%$ loss of the initial mass specific capacitance was observed in the cycling measurement after 2000 cycles. These results show that the as-prepared hierarchically porous carbon materials are promising candidates for high-performance supercapacitors.

\section{References}

[1] Liu, Chenguang, et al. "Graphene-based supercapacitor with an ultrahigh energy density." Nano letters 10 (2010): 4863-4868.

[2] Cai, Tingwei, et al. "Phenol-formaldehyde carbon with ordered/disordered bimodal mesoporous structure as high-performance electrode materials for supercapacitors." Journal of Power Sources 241 (2013): 6-11.

[3] Ra, E. J., et al. "High power supercapacitors using polyacrylonitrile-based carbon nanofiber paper." Carbon 47 (2009): 2984-2992. 
[4] Wang, Da - Wei, et al. "3D aperiodic hierarchical porous graphitic carbon material for high - rate electrochemical capacitive energy storage." Angewandte Chemie 120 (2008): 379-382.

[5] Gooch, Jan W. Encyclopedic dictionary of polymers. Vol. 1. Springer, 2010.

[6] Saha, Dipendu, et al. "Studies on supercapacitor electrode material from activated lignin-derived mesoporous carbon." Langmuir 30 (2014): 900-910.

[7] Chen, Feng, et al. "Self-assembly of NiO nanoparticles in lignin-derived mesoporous carbons for supercapacitor applications." Green Chemistry 15 (2013): 3057-3063.

[8] Kijima, Masashi, et al. "Thermal conversion of alkaline lignin and its structured derivatives to porous carbonized materials." Bioresource technology 102 (2011): 62796285.

[9] Ruiz - Rosas, R., et al. "Electrochemical performance of hierarchical porous carbon materials obtained from the infiltration of lignin into zeolite templates." ChemSusChem 7 (2014): 1458-1467.

[10] Zhang, Jiujun, et al., eds. Electrochemical technologies for energy storage and conversion. John Wiley \& Sons, 2012.

[11] Conway, Brian E. "Electrochemical supercapacitors." (1999).

[12] Kötz, R., and M. Carlen. "Principles and applications of electrochemical capacitors." Electrochimica Acta 45 (2000): 2483-2498.

[13] Frackowiak, Elzbieta. "Carbon materials for supercapacitor application." Physical Chemistry Chemical Physics 9 (2007): 1774-1785. 


\section{Chapter 6 Conclusions}

1. Both carbon materials and $\mathrm{LiMn}_{2} \mathrm{O}_{4}$ have been investigated to show the effects of specific surface area, hierarchical porous nano-structure, and surface functionality on the energy storage performance.

2. Flexible, self-sustained and hierarchically porous carbon nanofiber (CNFs) were fabricated. Macropores/mesopores in the fiber are beneficial to accelerate the iondiffusion into inner micropores.

3. An asymmetric supercapacitor $\mathrm{LiMn}_{2} \mathrm{O}_{4}$ nanoparticle //activated carbon was developed. The asymmetric supercapacitor cell showed a good energy capacity and excellent cycling stability.

4. Lignin was utilized in the thesis as carbon precursor to prepare mesoporous lignin-char. Hierarchically porous carbon (HPC) with pores at different scales were

obtained after alkali activation. A high capacitance of $237 \mathrm{Fg}^{-1}$ and excellent cycling stability were obtained. The good performance is ascribed to the unique porous structure: mesopores accelerating the ion-diffusion and micropores enhancing the capacitance value. 